\title{
EMT, the cytoskeleton, and cancer cell invasion
}

\author{
Mahmut Yilmaz • Gerhard Christofori
}

Published online: 24 January 2009

(C) Springer Science + Business Media, LLC 2009

\begin{abstract}
The metastatic process, i.e. the dissemination of cancer cells throughout the body to seed secondary tumors at distant sites, requires cancer cells to leave the primary tumor and to acquire migratory and invasive capabilities. In a process of epithelial-mesenchymal transition (EMT), besides changing their adhesive repertoire, cancer cells employ developmental processes to gain migratory and invasive properties that involve a dramatic reorganization of the actin cytoskeleton and the concomitant formation of membrane protrusions required for invasive growth. The molecular processes underlying such cellular changes are still only poorly understood, and the various migratory organelles, including lamellipodia, filopodia, invadopodia and podosomes, still require a better functional and molecular characterization. Notably, direct experimental evidence linking the formation of migratory membrane protrusions and the process of EMT and tumor metastasis is still lacking. In this review, we have summarized recent novel insights into the molecular processes and players underlying EMT on one side and the formation of invasive membrane protrusions on the other side.
\end{abstract}

Keywords Actin cytoskeleton - Cancer - Cell adhesion . EMT $\cdot$ Metastasis $\cdot$ Tumorigenesis

M. Yilmaz · G. Christofori $(\bowtie)$

Institute of Biochemistry and Genetics,

Department of Biomedicine, University of Basel,

Basel, Switzerland

e-mail: gerhard.christofori@unibas.ch

\section{Epithelial-mesenchymal transition (EMT) and metastasis}

Metastasis, the spread of tumor cells from a primary tumor to a secondary site within the human body remains one of the most life-threatening pathological events. In the last years, major efforts have been taken to understand the molecular mechanism underlying the distinct steps of metastasis, which are (i) detachment of tumor cells from the primary tumor, (ii) invasion into surrounding tissue, (iii) intravasation into blood or lymphatic vessels, (iv) dissemination in the blood stream or the lymphatic system and, finally, (v) extravasation and outgrowth at a secondary site. Each of these steps requires a distinct molecular program in which the modulation of the adhesive and migratory and, thus, the cytoskeletal properties of the disseminating tumor cells play essential roles.

To detach from the primary tumor and to invade into the surrounding tissue, tumor cells have to break down cell-cell contacts, remodel cell-matrix adhesion sites, and follow a chemoattractive path through the extracellular matrix, mined by secreted proteinases. These processes are commonly observed in various non-pathological conditions, such as in developmental processes like gastrulation or neural crest cell migration, where differentiated, epithelial cells dedifferentiate, move to a distant site, and then re-differentiate to form a new structure. This temporary and reversible phenomenon is known as the epithelial-mesenchymal transition (EMT), a process that is currently in the limelight of investigating the onset of cancer cell migration, invasion and metastatic dissemination $[1,2]$. During EMT, non-motile, polarized epithelial cells, embedded via cell-cell junctions in a cell collective, dissolve their cell-cell junctions and convert into individual, non-polarized, motile and invasive mesenchymal cells. Thereby, the molecular repertoire of a cell experiences 
dramatic changes. For example, the function and expression of the epithelial cell-cell adhesion molecule E-cadherin is lost, whereas the expression of the mesenchymal cell-cell adhesion molecule $\mathrm{N}$-cadherin is induced, a process also known as the cadherin switch. EMT can be prompted by various intrinsic signals (e.g. gene mutations) as well extrinsic signals (e.g. growth factor signaling). Among the growth factors known to induce EMT are transforming growth factor $\beta$ (TGF $\beta)$ [3], hepatocyte growth factor (HGF) [4], members of the epidermal growth factor (EGF) family [5], insulin-like growth factor (IGF)[6], and fibroblast growth factor (FGF) [7, 8]. Recently, also Notch signaling has been implicated in EMT in human breast cancer cells by activating the transcription factor Snail2 (Slug), a potent repressor of E-cadherin gene expression [9]. Changes in the composition of the extracellular matrix (ECM) are also able to induce EMT, as shown for collagen I and hyaluronan [10, 11].

With the diversity of signals inducing EMT the complexity of the interactive downstream effector pathways increases. Among the candidates which are engaged by TGF $\beta$-induced EMT are the small GTPases RhoA and Rac1 [12, 13], Ras [14], phosphoinositol-3 kinase (PI3K) [15], Mitogen-activated protein kinase (MAPK) [13], integrin-linked kinase (ILK) [16], and the Jagged1/Notch signaling pathway [17]. With increasing interest in microRNAs, miR-200 and miR-205 have been recently shown to play an important role in TGF $\beta$-induced EMT by modulating the function of ZEB1 $(\delta \mathrm{EF} 1)$ and ZEB2 (Sip1), transcriptional repressors of E-cadherin gene expression [18]. Such complexity of interactive signaling upstream and downstream of the induction of EMT also explains why EMT is not a simple matter of changes in a cell's adhesive capabilities or its cytoskeletal organization, it rather represents a fundamental reprogramming of almost every aspect of a cell's biology. Still, the different signaling cascades underlying EMT can be grouped into biological programs and, apparently, tumor cells undergoing EMT hijack programs that are central for developmental processes. The actual occurrence of EMT in patients is still highly debated, yet with more detailed molecular and histopathological analysis and the advent of novel markers there is increasing evidence identifying EMT in various human cancers [19, 20]. Still, many aggressive, invading tumors do not exhibit a molecular signature of EMT, suggesting that EMT may not be involved in every type of single cell invasion and that some tumors may undergo a partial or incomplete EMT [21]. In fact, cancer cells can invade in the absence of EMT and have a broad repertoire for invasion, including amoeboid or collective cell invasion [22, 23].

This review highlights recent novel insights into EMT research with a specific focus on the remodeling of the actin cytoskeleton and the formation of invasive structures during EMT and tumor cell invasion.

\section{Epithelial cell-cell adhesion}

The formation of a stable, polarized epithelium requires tight cell-cell and cell-matrix connections. E-cadherin is the major component of epithelial adherens junctions (AJ) which mediate, along with tight junctions, intercellular adhesion. $\mathrm{AJ}$ are located basal to the apical tight junctions (TJ) and form a belt-like structure which tie neighboring cells together (zonula adherens). E-cadherin is the prototype family member of classical cadherins, single-span transmembrane glycoproteins that interact in a calcium-dependent, homophilic manner with E-cadherins on neighboring cells. E-cadherin-mediated cell-cell adhesion complexes are anchored to the actin cytoskeleton via its cytoplasmic domain and $\beta$-catenin and $\alpha$-catenin (Fig. 1 a). Thus, the formation of E-cadherinmediated cell-cell adhesion fundamentally modulates the organization of cytoskeleton. This classical view of a direct connection between the E-cadherin $/ \beta$-catenin $/ \alpha$-catenin complex and the actin network has been challenged by recent studies demonstrating that a reconstructed cadherincatenin complex fails to bind actin filaments in vitro [24], and that E-cadherin, localized in electron-dense microdomains called spot adherens junctions (SAJs), binds to actin in an $\alpha$-catenin-independent manner [25]. Here, the authors describe a model in which two distinct actin populations are involved in the zonula adherens architecture (Fig. 1 a). One population represents stable, non-dynamic patches of highly organized actin to which the E-cadherin/ $\beta$ catenin complex is attached in an $\alpha$-catenin-independent manner (SAJs). The second population of actin is an underlying, dynamic actin framework to which the SAJs are linked and correctly positioned by $\alpha$-catenin. One protein replacing $\alpha$-catenin in the E-cadherin/ $\beta$-catenin complex to SAJ could be eplin, a newly identified actin-binding protein [26]. The juxtamembrane domain of E-cadherin binds to p120-catenin which is important in surface tracking, lysosomal degradation and correct membrane localization of Ecadherin [27-30]. Furthermore, p120-catenin plays an elementary role in the stability of epithelial cell-cell adhesion by repressing the activity of RhoA and activating Rac and Cdc42 [31-33]. All three GTPases are key regulators of actin assembly and play an essential role in the stability of cell-cell adhesion by enforcing actin stress fibers (RhoA) and the formation of migratory membrane protrusions, such as lamellipodia and filopodia ( $\mathrm{Rac}$ and $\mathrm{Cdc} 42$, respectively), as discussed below.

Besides its adhesive function, E-cadherin also encompasses signaling capabilities, transduced predominantly by proteins interacting with its intracellular domain, such as $\beta$ - 


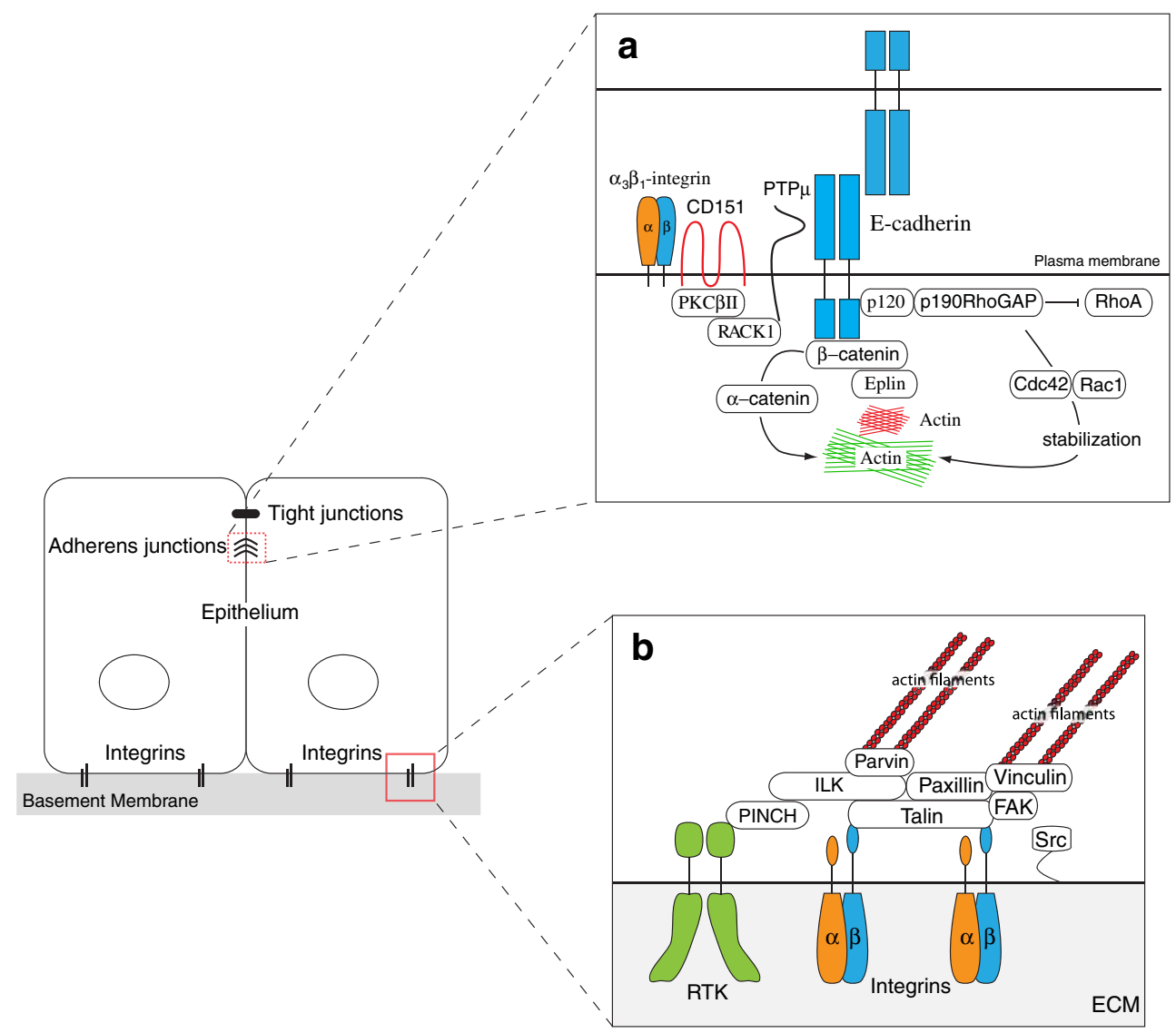

Fig. 1 Differentiated, polarized epithelial cells are tightly attached to their neighboring cells by E-cadherin-mediated cell-cell adhesion complexes and to the extracellular matrix via integrins. a Epithelial cell-cell adhesion. E-cadherin is connected via $\beta$-catenin and Eplin to stable, electron-dense actin microdomains called spot adherens junctions (SAJ) in an $\alpha$-catenin-independent manner. These ECadherin-SAJs complexes are attached and correctly positioned to an underlying dynamic actin framework via $\alpha$-catenin. E-cadherinmediated cell adhesion is stabilized by (i) p120-catenin recruited p190RhoGAP, which stabilizes the actin cytoskeleton underlying the adhesion complex by balancing the activities of RhoA and Rac1/ $\mathrm{Cdc} 42$, and by (ii) protein tyrosine phosphatase $\mathrm{PTP} \mu$, which keeps $\beta$ - catenin in an dephosphorylated state thereby preventing its degradation. $\mathrm{PTP} \mu$ is correctly positioned to $\beta$-catenin by a multimeric protein complex consisting of receptor of activated protein kinase $\mathrm{C}-1$ (RACK1), protein kinase $\mathrm{C}-\beta \mathrm{II}$ (PKC $\beta \mathrm{II})$, the tetraspanin CD151 and $\alpha_{3} \beta_{1}$-integrin. b Epithelial cell-matrix adhesion. Integrin-mediated cell-matrix adhesion and linkage to the actin cytoskeleton is accomplished by a multiprotein complex consisting of the adaptor proteins talin, paxillin, vinculin and the ternary complex of pinch, parvin and integrin-linked kinase (ILK), called tIPP complex. The interaction and phosphorylation status of focal adhesion kinase (FAK) and the non-receptor tyrosine kinase Src is critical for integrin complex assembly and turnover catenin, or receptors that form multimeric complexes with Ecadherin, such as c-Met, the cognate receptor for HGF, IGF1R or integrins [34]. Notably, E-cadherin has been shown to interact with a multimeric complex that consists of $\alpha_{3} \beta_{1}$ integrin, the tetraspanin CD151, which recruits protein kinase $\mathrm{C}-\beta \mathrm{II}$ (PKC $\beta \mathrm{II})$, receptor of activated protein kinase $\mathrm{C}-1$ (RACK1), and the transmembrane protein tyrosine phosphatase PTP $\mu$ [35] (Fig. 1 a). This multimeric complex promotes association of the cadherin-catenin complex with the actin cytoskeleton and supports cadherin mediated cellcell adhesion. CD151 appears to be important for the filopodia-based "adhesion zipper formation", a process by which initial filopodia-mediated contacts of epithelial cells develop into mature cell-cell junctions [36, 37]. Moreover, CD151 expression accelerates E-cadherin-mediated intercel- lular adhesion by inducing Cdc42-induced filopodia extensions which form initial cell-cell contacts. Consistent with these observations, E-cadherin colocalizes and interacts with cortactin, a key regulator of actin-cytoskeleton assembly and remodeling [38].

E-cadherin also associates with c-Met, IGF1R and $\alpha_{\mathrm{v}}$ integrin at the plasma membrane [39, 40]. Interestingly, in the absence of $\alpha$-catenin the E-cadherin/IGF1R complex does not form, suggesting that $\alpha$-catenin besides its function as actin-anchoring protein also exerts a function as an important scaffolding protein. Upon stimulation with IGF-I, $\alpha_{\mathrm{v}}$-integrin dissociates from the cell-cell adhesion complex and translocates to focal contact sites of invasive structures, such as invadopodia (see below). These findings expand E-cadherin's functional repertoire beyond its adhe- 
sive functions and emphasize the critical role of E-cadherin as a regulator of signaling complexes.

\section{Loss of E-cadherin function and its consequences}

Loss of E-cadherin gene expression or of E-cadherin protein is frequently found during tumor progression in most epithelial cancers. Hence, loss of E-cadherin function is a clinical indicator for poor prognosis and metastasis [41-43]. Since E-cadherin plays a key role in epithelial structure and homeostasis its expression underlies a strict control. As many other proteins, E-cadherin can be regulated at the transcriptional as well as at the posttranslational level, yet both mechanisms usually cooperate for an efficient repression of E-cadherin function.

\subsection{Transcriptional control of E-cadherin}

Transcriptional repression of E-cadherin is mediated by a list of transcription factors, among them intensely studied

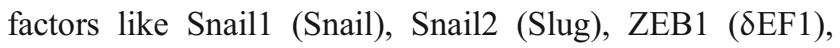
ZEB2 (Sip1), E47, and Twist [44] (Fig. 2 a). The expression of these repressors can be induced by a variety of stimuli, including activation of the TGF $\beta$, HGF, EGF, Wnt, and Notch signaling pathways. Moreover, they seem to regulate each other's expression in positive and negative feedback loops. Engagement of these transcriptional repressors at the E-cadherin gene promoter eventually leads to epigenetic silencing of the gene by histone modifications (acetylation, methylation, phosphorylation, ubiquitinylation, sumoylation) and subsequently by DNA hypermethylation [45-47]. Such silencing of the E-cadherin promotor is a complex process [48]. As a first step, Snail1 recruits the histone deacetylase HDAC to the E-cadherin promotor complex, thereby inducing histone deacetylation. Subsequently, the polycomb repressor complex 2 (PRC2) is recruited to the site and methylates histones, thus supporting E-cadherin repression. Upon initial down-regulation of E-cadherin gene expression, Snail1 induces ZEB1 expression, which in turn engages a second, PRC2-independent repressor complex that further inhibits E-cadherin expression. In addition, new interaction partners of Snaill have been identified, such as the LIM-domain protein Ajuba which recruits the protein arginine methyltransferase 5 (PRMT5) to support Snail1-mediated transcriptional repression [49]. In a large variety of human cancers, the Ecadherin gene is found to be highly hypermethylated, yet how the initial silencing of the gene promoter converts into a more long-term repression by DNA hypermethylation remains to be resolved [50]. In the context of EMT and the metastatic dissemination of tumor cells, the molecular basis of the reversibility or irreversibility of E-cadherin's epige- netic silencing is thus a future challenge. This complexity and/or variability in E-cadherin regulation indicates that the cell has a dynamic range of E-cadherin expression and depending on the actual need can either totally suppress or temporally attenuate its expression.

\subsection{Post-translational control of E-cadherin}

On the post-translational level, the transport of newly synthesized E-cadherin to the cell membrane can be inhibited via O-glycolysation [51] or mature, membranebound E-cadherin can be degraded by proteolytic cleavage or endocytosed from the plasma membrane [52-55]. The proteolytic cleavage of E-cadherin can also produce Ecadherin fragments which exert signaling functions. For example, $\gamma$-secretase-mediated cleavage of E-cadherin produces a $\mathrm{C}$-terminal, cytoplasmic fragment (CTF2) that is transported into the nucleus in a p120-catenin-dependent manner (Fig. 2 b). In the nucleus, CTF2 modulates the interaction between p120-catenin and Kaiso, a transcriptional repressor, thereby affecting for example cell survival [56]. Destabilization of the E-cadherin adhesion complex is also accomplished by receptor tyrosine kinase or Srcmediated phosphorylation of E-cadherin, followed by its ubiquitylation by the E3 ligase Hakai and subsequent degradation [57, 58] (Fig. 2 b). Moreover, integrinactivated focal adhesion kinase (FAK) can phosphorylate $\beta$-catenin and thus induce its ubiquitylation and degradation and the disassembly of the E-cadherin cell adhesion complex [59]. Endocytosis of E-cadherin can occur via clathrin or caveolin-dependent mechanisms [60-62]. A key player in clathrin-mediated E-cadherin endocytosis is Arf6, a Ras-related small GTPase. It promotes endocytosis via recruitment of Nm23-H1, a nucleoside diphosphate kinase (and the first metastasis suppressor gene ever identified [63]), which in turn activates dynamin-dependent fission of vesicles and destabilization of cortical actin by recruiting the guanine nucleotide exchange factor (GEF) Tiam1, a Rac1 inhibitor [64]. Recently, a new GTPase activating protein (GAP) for Arf6, Smap1, has been identified, which plays an essential role in E-cadherin endocytosis, revealing a new player in post-translational E-cadherin control $[65$, 66].

The downregulation of E-cadherin not only leads to a mechanical disruption of $\mathrm{AJ}$, it also liberates proteins from the cytoplasmic cell adhesion complex which exert ambivalent functions depending on their subcellular localization. The probably most prominent cytoplasmic interaction partner of E-cadherin is $\beta$-catenin, well known for its dual role in cell adhesion and Wnt signaling [67]. Stabilized by active Wnt signaling or by mutations in the $\beta$-catenin phosphorylation/degradation pathway, $\beta$-catenin accumulates in the cytoplasm and enters the nucleus where it 


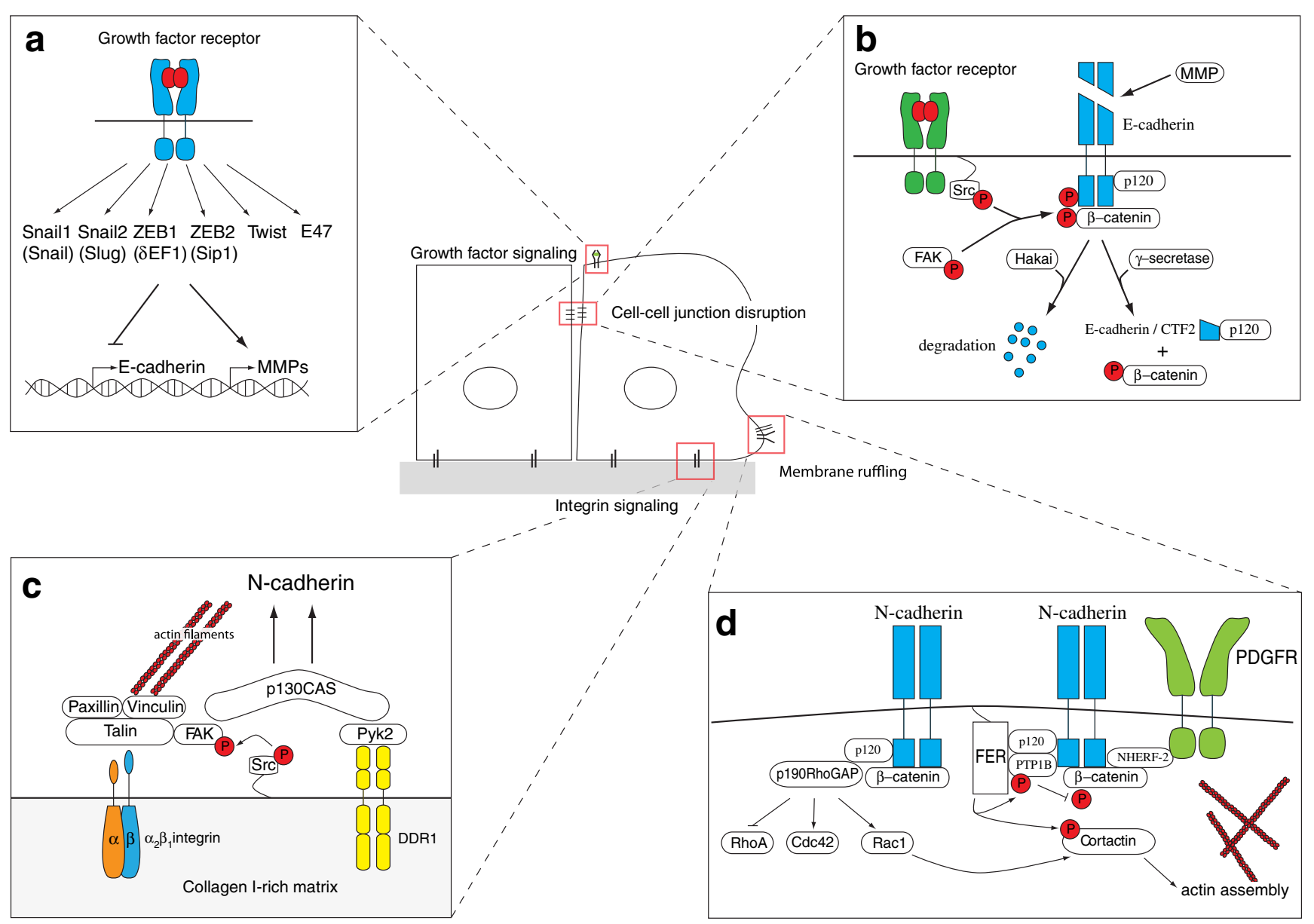

Fig. 2 Induction of epithelial-mesenchymal transition (EMT). a Repression of E-cadherin gene expression. Growth factor stimulation induces various signaling cascades leading to the induction of EMT. Among the regulated genes are transcription factors that repress Ecadherin gene expression and induce expression of genes such as matrix metalloproteinases (MMP). b Loss of E-cadherin function. The Ecadherin cell-cell adhesion complex is destabilized by Src and/or FAKmediated phosphorylation of either E-cadherin or $\beta$-catenin. The phosphorylation of the cytoplasmic E-cadherin domain induces its proteasomal degradation mediated by the E3-ubiquitin-ligase Hakai. Phosphorylation of $\beta$-catenin induces its detachment from E-cadherin and relocalization into the nucleus, where together with Tcf transcriptions factors modulates the expression of pro-invasive genes. Intracellular cleavage of E-cadherin by $\gamma$-secretase also results in a loss of E-cadherin function, yet its newly generated C-terminal fragment (CTF2) together with p120-catenin translocates into the nucleus, where it modifies the activity of the transcriptional repressor Kaiso. c Integrin-

interacts with members of the Tcf/Lef family of transcription factors and modulates expression of a large number of genes involved in cell proliferation, migration, invasion, and morphogenesis, including cyclin D1, the cell adhesion molecule L1-CAM, matrix metalloproteases (MMP) and the metastasis gene S100A4 [68, 69]. Another recently discovered target of $\beta$-catenin/Tcf signaling is Fascin, a actin-bundling protein which is essential for filopodia formation and cancer cell invasion [70, 71]. mediated support of EMT. Enrichment of collagen I in the extracellular matrix supports EMT via the coordinated signaling of $\beta_{1}$-integrins and the collagen receptor DDR1. These signals converge via FAK and Pyk2 kinases on the $130^{\mathrm{Crk}}$-associated scaffold (CAS) protein, resulting in the induction of $\mathrm{N}$-cadherin expression. $\mathbf{d}$ The formation of protrusive membrane structures. Upon PDGF stimulation, N-cadherin co-localizes with PDGFR in membrane ruffles. The interaction of both $\mathrm{N}$-cadherin and PDGFR relies on $\mathrm{Na}^{+} / \mathrm{H}^{+}$exchanger regulatory factor-2 (NHERF-2) which is recruited to the complex by p120-catenin. Localized in membrane ruffles, $\mathrm{N}$-cadherin contributes to actin cytoskeleton remodeling (i) by recruiting p190RhoGAP and thereby favoring Rac1 and or Cdc42-mediated actin remodeling and (ii) by employing p120-catenin to recruit the non-receptor tyrosine kinase Fer. Fer in turn phosphorylates and activates cortactin which induces actin assembly. Morover, Fer stabilizes the $\mathrm{N}$-cadherin complex by phosphorylating and activating protein tyrosine phosphatase PTP1B, thus preventing $\beta$-catenin phosphorylation and degradation

Similar to $\beta$-catenin, upon loss of E-cadherin function, p120-catenin is also freed from the cytoplasmic cell adhesion complex and accumulates in the cytoplasm. In addition to its functions on Rho family GTPases and the actin cytoskeleton (see above), p120-catenin can traffic to the nucleus where it binds to the transcriptional repressor Kaiso. In contrast to $\beta$-catenin/Tcf-mediated transcription, where $\beta$-catenin acts as a transactivator, p120-catenin has no transactivation domain and rather releases Kaiso from its 
promoter binding sites and thus activates gene expression by de-repression. However, the nature of p120/Kaiso target genes is still poorly defined [72].

\section{The cadherin switch and its consequences}

The loss of epithelial E-cadherin and the gain of mesenchymal N-cadherin expression is a major hallmark of EMT. This cadherin switch leads to a drastic change in the adhesive properties of a cell, as it loses its affinity for epithelial neighbors and gains affinity for mesenchymal cells, such as fibroblasts or vascular endothelial cells. Besides the change of the adhesive repertoire, the gain of $\mathrm{N}$-cadherin expression also provokes increased cell migration and invasion [73, 74]. Like E-cadherin, N-cadherin belongs to the family of classical cadherins and forms homophilic cell-cell adhesion junctions. N-cadherin is normally expressed in nervous tissue, in vascular endothelial cells, and in skeletal and cardiac muscle cells. Its expression is upregulated in the cells of the primitive streak during mesoderm formation and during progression of a variety of cancers, where its expression correlates with poor prognosis [74-76]. Investigations into the molecular mechanisms underlying the induction of $\mathrm{N}$-cadherin expression during EMT have only recently begun. It has been shown that $\mathrm{N}$-cadherin can be upregulated by collagen I via the coordinated engagement of the collagen receptor discoidin domain receptor 1 (DDR1) and $\alpha_{2} \beta_{1}$-integrin based on a p130 ${ }^{\text {Crk }}$-associated substrate (CAS) scaffold [10, 77] (Fig. 2 c). On the transcriptional level, the transcriptional repressor Twist appears to be involved in the induction of $\mathrm{N}$-cadherin gene expression in an $\beta_{1}$-integrin-dependent manner [7880].

Like its epithelial counterpart, $\mathrm{N}$-cadherin is connected via $\alpha$-catenin and $\beta$-catenin to the cytoskeleton and functions as both a mechanical cell adhesion component and a signaling molecule. Recently, it has been reported that during neurite extension the traction forces generated by retrograde actin flow are directly transmitted to $\mathrm{N}$-cadherin adhesions, thereby mechanically linking $\mathrm{N}$-cadherin with the formation of motile structures [81]. Interestingly, the authors show that the mechanical engagement of $\mathrm{N}$ cadherin induces local actin polymerization and thereby ensures the integrity of the adhesion complex. Engagement of N-cadherin activates the RhoGTPase Rac1, which in turn recruits the actin remodeling protein cortactin to the $\mathrm{N}$ cadherin adhesion complex [82] (Fig. 2 d). Within this complex, the non-receptor tyrosine kinase Fer associates with $\mathrm{N}$-cadherin via p120-catenin [83]. Fer then phosphorylates and activates cortactin, thereby inducing actin remodeling, and increasing the mobility of $\mathrm{N}$-cadherin molecules to extend the adhesion zone and, finally, to promote the formation of stable cell-cell adhesion. In line with these observations, $\mathrm{N}$-cadherin is found to be localized in the lamellipodia of adjacent, contacting myoblasts [84]. Fer also phosphorylates the phosphatase protein tyrosine phosphatase 1B (PTP1B) and promotes its binding to Ncadherin. The PTP1B/N-cadherin interaction protects $\beta$ catenin from degradation by keeping it in a dephosphorylated state and thereby ensures the stability of the N-cadherinmediated cell-cell junctions [85, 86] (Fig. 2 d).

Also similar to E-cadherin, N-cadherin interacts with a number of signal transduction molecules and contributes to various signaling pathways. For example, $\mathrm{Na}+\mathrm{H}+$ exchanger regulatory factor (NHERF)-2 has been shown to physically link N-cadherin to PDGF receptor (PDGFR) by binding both $\beta$-catenin in the $\mathrm{N}$-cadherin $/ \beta$-catenin complex and PDGFR [87] (Fig. 2 d). PDGFR activation is known to induce actin reorganization and cell proliferation and differentiation and to play an important role in EMT [88, 89]. Interestingly, PDGF stimulation of NIH3T3 cells leads to colocalization of N-cadherin, p120-catenin and p190RhoGAP in dorsal circular ruffles (DCRs), structures known to depend on growth factor-induced Rac activity and subsequent RhoA inhibition [90-92]. This is interesting because p120-catenin is not only important for the recruitment of Fer to the N-cadherin complex, but together with p190RhoGAP also coordinates the antagonistic functions between Rac and RhoA [31, 93]. This antagonism plays a critical role in defining the structure of the actin cytoskeleton. The active form of RhoA stimulates focaladhesion (FA) formation and contractility via assembly of predominantly radially-oriented actin stress fibers (ASF), whereas Rac activation induces cell spreading, migration and membrane ruffling via actin polymerization at the cell periphery. Moreover, Rac activation inhibits Rho activity, which can also be achieved by p120-catenin over-expression [94] (Fig. 2 d).

Besides PDGFR, N-cadherin also interacts with FGF receptors (FGFR) in a complex with neural cell adhesion molecule (NCAM), a immunoglobulin domain cell adhesion molecule $[42,95]$. The interaction between $\mathrm{N}$-cadherin and FGFR leads to stabilization of FGFR at the membrane surface by preventing its internalization upon ligand binding. As a result, sustained MAPK pathway activation and increased cell motility and MMP secretion promote invasiveness of N-cadherin-expressing cells [96-98]. NCAM accomplishes a similar induction of cell migration and invasion by directly binding and stimulating FGFR via its fibronectin type III domains [95]. Thereby, NCAMmediated stimulation of FGFR signaling differs substantially from FGF-induced FGFR signal transduction resulting into different cellular outcomes, such as increased cell-substrate adhesion, migration and invasion by NCAM and cell proliferation by FGF [99]. The interaction between $\mathrm{N}$ - 
cadherin and NCAM with FGFR relies on a CAM-domain proximally located to the acid box region of the FGFR, which is not required for FGF ligand binding [100]. Such complex interactions between different cell adhesion molecules and tyrosine kinases raise another level of complexity in the regulation of cell migration, invasion and metastasis formation. For a more detailed insight into specific aspects of cell adhesion and signaling complexes at the invasive cancer front we refer the reader to recently published reviews [42, $101]$.

Like E-cadherin, N-cadherin is also proteolytically processed to generate shedded extracellular domain and intracellular domain fragments with potential signaling functions. In neurons, N-cadherin is cleaved by ADAM10 and by $\mathrm{PS} 1 / \gamma$-secretase to produce a cytoplasmic fragment of N-cadherin, N-Cad/CTF2, for example stimulated by bone morphogenic protein-4 (BMP4) [102, 103]. N-Cad/ CTF2 is able to interfere with the $\mathrm{CPB} / \mathrm{CREB}$ transcription complex, by binding the transcription factor $\mathrm{CBP}$ and inducing its proteasomal degradation. N-Cad/CTF2induced repression of $\mathrm{CPB} / \mathrm{CREB}-$ mediated transcriptional control suppresses expression of genes important for proliferation and differentiation, such as c-Fos. N-Cad/ CTF2 also promotes migration of neural crest cells by increasing the expression of $\beta$-catenin and therewith inducing the expression of $\beta$-catenin target genes like cyclin D1. Interestingly, N-Cad/CTF2 facilitates $\beta$-catenindependent signaling (i) by inhibiting $\beta$-catenin phosphorylation, (ii) by increasing $\beta$-catenin transcription and (iii) by reducing full-length $\mathrm{N}$-cadherin protein levels to prevent sequestration of $\beta$-catenin to cell-cell junctions [104].

These data describe $\mathrm{N}$-cadherin as a critical protein in the regulation of EMT and cell invasiveness. Besides simply exercising a cell adhesion function that changes a cell's affinity from epithelial cells to mesenchymal cells, it is actively involved in delineating a cell's migratory state by modulating growth factor signaling and remodeling the actin cytoskeleton. Such pleiotropic functions certainly warrant detailed future experimental investigations.

\section{Integrin-mediated cell-matrix adhesion and signaling}

The extracellular matrix (ECM) is a constantly remodeled $3 \mathrm{D}$ structure consisting of a variety of specialized proteins and proteoglycans which are able to regulate many cellular processes, including cell proliferation, survival, differentiation, and migration. This control is mainly based on a constant communication between the adhesive adaptors of a cell, integrins, and the ECM. Changes of a cell's integrin repertoire or the composition of the ECM can have drastic consequences for the cell and, in extremis, can lead to cell death as well as transformation. Besides its scaffolding function, the ECM is also able to bind and sequester diverse growth factors and chemokines which can be retrieved by local proteolysis and, dependent on activation or inactivation, affect cell behavior. Integrins are heterodimeric type-I transmembrane proteins consisting of an $\alpha$-and a $\beta$-chain. Mammals have $18 \alpha$ and $8 \beta$ chains which are combined to generate 24 different combinations which bind in a specific, yet partially overlapping, manner various components of the ECM.

Similar to cadherins, also integrins function as both mechanical adhesion and signaling molecules. Importantly, integrins switch between an inactive, low ligand-affinity conformation and an active, high ligand-affinity conformation. Activation can be achieved by binding of intracellular proteins to integrins, such as talin, or by MMP-mediated proteolytic cleavage $[105,106]$. Integrins are linked to the actin cytoskeleton and signal via the ternary complex of integrin-linked kinase (ILK), pinch and parvin, also named the tIPP complex [107] (Fig. 1 b). In the tIPP, integrins are linked through ILK to the actin cytoskeleton, either via parvin itself or via a paxillin/vinculin/parvin complex. ILK plays a major role as a scaffold protein in assembling the multimeric protein complex which is necessary for the integrin-actin cytoskeleton linkage (via parvin, paxillin and vinculin). Moreover, ILK is required for the formation of signaling complexes with receptor tyrosine kinases via pinch. The signaling cascades triggered by the activation of integrins and its cytoplasmic partners are complex. Among the direct targets downstream of integrins are FAK, Srcfamily kinases, glycogen synthase-kinase-3 $\beta$ (GSK3 $\beta$ ) and protein kinase $\mathrm{B}$ (AKT/PKB). Effectors of these signaling cascades include MAPK, NFKB, Jun, $\beta$-catenin and others and together they modulate cell proliferation, cell survival, cell migration and invasion. Among the mitogenic integrins are $\alpha_{6} \beta_{4}$ or $\alpha_{v} \beta_{3}$-integrins which cooperate with diverse growth factor receptors, including EGFR, ErbB2, and c-Met [108-111]. On the other hand, growth inhibitory signals can be transmitted, for example via $\alpha_{2} \beta_{1}$-integrin, which in turn activates p38-MAPKmediated cell-cycle inhibition $[112,113]$. Integrin $\alpha_{v} \beta_{6}$ or $\alpha_{\mathrm{v}} \beta_{8}$ engagement leads to the activation of latent TGF $\beta$ thereby executing its cytostatic effect [114, 115]. Faced by this dichotomy of integrin signaling, cancer cells switch their integrin expression to a pro-oncogenic repertoire in order to invade and survive in the surrounding tissue.

\section{Integrins in EMT and cell invasion}

The function of integrins during EMT is diverse and dynamic as they are able to initiate and enforce EMT and invasion. For example, engagement of integrins $\alpha_{1} \beta_{1}$ or $\alpha_{2} \beta_{1}$ by collagen type I results in a loss of E-cadherin 
mediated cell-cell contacts, along with the activation of the $\beta$-catenin/Tcf pathway in pancreatic cancer cells $[59,116]$. Furthermore, as described above, collagen type I is also able to induce $\mathrm{N}$-cadherin expression upon activation of the integrin $\alpha_{2} \beta_{1}$ together with the collagen receptor discoidin domain receptor 1 (DDR1), a receptor tyrosine kinase [77]. Both, the downregulation of E-cadherin and upregulation of $\mathrm{N}$-cadherin play important roles in the initiation and execution of EMT. Interestingly, Snail1, the transcriptional repressor of E-cadherin expression and a potent inducer of EMT, is able to induce the expression of $\alpha_{v} \beta_{3}$-integrin which is well known for its pro-invasive functions and its localization in the invading front of cancers $[117,118]$.

Along with their function as mechanical anchor proteins for cell migration and invasion, integrins play an important role in the correct localization of proteases. Several reports demonstrate that the colocalization and cooperation of $\beta 1$ integrin and MT1-MMP1 is necessary for cancer cell invasion into a collagen matrix and that both MT1-MMP and $\beta_{1}$-integrins have important roles in EMT [119-123]. The localization of MT1-MMP to $\beta_{1}$-integrins is an exocytic event dependent on the activity of the GTPase Rab8 [124]. Integrin-mediated recruitment of ECM remodeling proteases is also responsible for the liberation and/or activation of matrix bound growth factors and chemokines. As described above, the cooperation of MT1-MMP and $\alpha_{\mathrm{v}} \beta_{8}$-integrin leads to the activation of latent TGF $\beta$ [115, $125]$. TGF $\beta$ usually acts as a cytostatic, tumor suppressing factor, but it promotes tumor progression and invasion, if the tumor cells overcome its cytostatic and apoptotic effects [126]. In fact TGF $\beta$ is one of the most potent inducers of EMT in cultured cells in vitro and in animal models in vivo [1]. Other integrins which are upregulated during EMT, such as $\alpha_{v} \beta_{6}$-integrin, are also able to increase protease expression and to liberate and activate TGF $\beta$ [127-129]. Also, the activities of the cytoplasmic interaction partners of integrins, ILK and pinch, have been implicated in the process of EMT [130-132].

\section{EMT and the actin cytoskeleton}

The actin cytoskeleton is a highly dynamic structure, which is constantly remodeled in a living cell. This dynamics are based on a well-balanced and highly controlled equilibrium of local assembly and disassembly of actin filaments. Obviously, such regulation is a prerequisite for processes like endocytosis, cell motility, and cancer cell invasion.

\subsection{RhoGTPases and EMT}

The members of the Rho GTPase family are mainly responsible for integrating and transmitting signals from chemokine and growth factor receptors and from adhesion receptors to effector proteins of actin remodeling. RhoGTPases are activated upon GTP binding and inactive in their GDP-bound form. RhoGTPase activation is tightly controlled by three groups of regulatory proteins, guanine nucleotide exchange factors (GEF), GTPase-activating proteins (GAP), and guanine nucelotide dissociation inhibitors (GDI). GEF are responsible for the activation of RhoGTPases by promoting the exchange of Rho-bound GDP by GTP. This is counteracted by GAP which raise the intrinsic GTPase activity of RhoGTPases and the hydrolysis of bound GTP to GDP. Finally, GDI bind inactive RhoGDP and prevent the interaction with RhoGEFs and thus its activation. RhoA, Rac1 and Cdc42 are best studied among the 23 family members of RhoGTPases. The complexity of RhoGTPase signaling arises not only from the size of its family members and number of effector proteins $(\sim 70$ proteins), but also from the numbers of GEF $(\sim 70$ members), GDI ( $\sim 3$ members) and GAP ( $\sim 60$ members $)$ which modulate their activity. Depending on which GEF, GDI or GAP is interacting with the RhoGTPase the biological response can be different. In the GTP-bound form, RhoGTPases activate effector proteins, which are often serine/threonine kinases, such as the p21-activated kinases (PAK) for Rac1 and Cdc42 and the ROCK kinases for RhoA. In general, RhoGTPases affect almost all cell biological processes in a cell's life [133-135]. With regard to migration and invasion and in a simplified view, RhoA induces actin stress fiber formation and regulates cytoskeletal changes affecting cell-cell or cell-matrix adhesion, Rac1 is involved in lamellipodia and membrane ruffle formation, and $\mathrm{Cdc} 42$ is involved in filopodia formation $[136,137]$. Based on their central function in actin remodeling and their ability to induce MMPs, Rho GTPases play an important role in EMT as well [138].

During growth factor-induced EMT, tight control of the activities of RhoGTPases is critical. As mentioned above, depending on the presence of epithelial or mesenchymal cadherins, the localization and function of p120-catenin and thus the activity of RhoGTPases change dramatically [139]. In epithelial cells, p120-catenin localizes at the cell membrane and associates with E-cadherin where it controls the activity of RhoA and Rac1. RhoA activity, which is required for the initial cell-cell contact formation, is downregulated in established, mature cell adhesions. Both, activation and inactivation of RhoA require the p120catenin-dependent recruitment of RhoGEFs, like Vav2, or RhoGAPs, like p190-RhoGAP, respectively. The recruitment of p190-RhoGAP results in the activation of Rac1 which leads to a stabilization of E-cadherin junctions by inhibiting the activities of IQ-domain GTPase-activating protein 1 (IQGAP1), a Rac1 effector protein and a mediator of E-cadherin endocytosis (see also below). Moreover, the 
actin cytoskeleton underlying cell contacts is reorganized and stabilized [140].

During EMT, p120-catenin binds to mesenchymal cadherins at the cell membrane but is also found localized in the cytoplasm. Cytoplasmic p120-catenin functions as a RhoA-GDI that binds and represses RhoA activity [141]. Simultaneously, p120-catenin bound to mesenchymal cadherins at the cell membrane promotes Rac1 activity and induces the formation of motile, protrusive membrane structures, such as lamellipodia. Thus, both cytoplasmic and membrane-sequestered p120-catenin cooperate to induce cell motility during EMT. Interestingly, Rac1 inhibits RhoA activity by inducing the production of reactive oxygen species (ROS), which in turn activate p190RhoGAP by inhibiting the low-molecular weight protein tyrosine phosphatase (LMW-PTP) [90, 142]. Moreover, the expression of Snail1, the transcriptional repressor of Ecadherin gene expression and potent inducer of EMT, is is increased upon Rac1-mediated ROS production [143]. The importance of RhoGTPases in EMT is also underscored by the notions that Raclb, a splice variant of Rac1, is highly expressed in malignant breast tissue, that RhoA downregulation is required for EMT in colon carcinoma progression, and that Rock activity is critical for cell migration, invasion and metastasis after EMT [141, 144, 145].

The activity of RhoA during EMT not only effects cellcell adhesion but also microtubule-mediated cell-matrix adhesion and basement membrane integrity [146]. RhoA, when localized at the cell-basement membrane (BM) gets in contact with Net1, a RhoA-specific GEF, thereby exerting an important function for the integrity of the $\mathrm{BM}$ in epiblasts. During gastrulation, a process resembling EMT, RhoA at the cell basis loses its activity, which leads to microtubule destabilization, cell-BM contact disruption and BM breakdown. Notably, destabilization of the cell-BM contacts precedes breakdown of cell-cell adhesions.

Tiam1, a GEF for Rac1, also exerts a critical function in both E-cadherin-mediated cell-cell junction stability and during EMT. Loss of Tiam1 activity is required for the induction of EMT; forced expression of constitutive-active forms of Rac1 (RacV12) or Tiam-1 prevents HGF-induced EMT in epithelial cells [147, 148]. Interestingly, ablation of Tiam-1 in a mouse model of chemical-induced skin carcinogenesis reduces tumor incidence yet increases tumor malignancy, demonstrating the ambivalent role of Rac1 in tumor formation and tumor progression [149].

Despite major progress, the detailed role of Rho family GTPases in EMT and tumor progression still remains unresolved. The sophistication of tumor cell motility and invasion on one side and the immense complexity of the regulation of RhoGTPases on the other side obscure a simple solution. The formation of membrane protrusions and other RhoGTPase-dependent activities during EMT are not linear processes, and rather depend on the integrated activities of many members of the RhoGTPase family and their interaction with various regulatory proteins which will eventually determine the time and localization of their specific activities.

\subsection{Membrane ruffles}

The onset of motility requires a relaxation of static actin structures in order to form pliable membrane protrusions. Rigid actin stress fibers are disassembled upon dorsal circular ruffle (DCR) formation leaving a fine cortical actin meshwork behind, from which cell membrane protrusions like lamellipodia can emerge $[150,151]$. DCRs are shortlived actin structures formed at the dorsal surface of growth factor (PDGF, HGF, EGF)-stimulated cells. DCRs, formed at the leading edge of growth factor-stimulated cells, are also able to secrete MMP (e.g. MMP-2), revealing their potential role for the onset of cell invasion [152]. Besides relaxing static membrane structures, DCRs are also important for macropinocytosis in growth factor-stimulated epithelial cells [153, 154]. Macropinocytosis plays an important role in the modulation of cell signaling; it may either inhibit signal transduction via degradation of growth factor receptor complexes or it may potentiate signaling, as shown in the case of EGF [154]. DCRs are enriched with actin assembly proteins, such as Arp2/3, WASP and cortactin, suggesting that DCR formation requires actin assembly. As mediators of growth factor signaling, RhoGTPases, like Rac1 or Cdc42, are required for DCRs formation as well [155]. Other reports indicate the involvement of protein kinase A (PKA) and the cytoplasmic tyrosine kinase Abl in DCR formation [156]. Both, PKA and Abl, are known to be involved in EMT [157159].

$\beta$-catenin in a complex with APC is also found to be localized at the leading edge of migratory cells, implying an important role for cell polarization and migration by linking microtubules to the actin cytoskeleton [160-162]. Notably, $\beta$-catenin seems to exert its function at the leading edge of cells by co-localizing with $\mathrm{N}$-cadherin and IQGAP1 in membrane ruffles [118]. IQGAP1, an effector of Cdc42 and Rac1, here acts as a key regulator of internalization of $\mathrm{N}$ cadherin and APC. The fact that PDGFR also co-localizes with $\mathrm{N}$-cadherin in membrane ruffles suggests an interesting overlap of proteins known to be important in both EMT and ruffle or podosome formation [87].

Other newly identified players in DCR formation and important for motility are palladin and its interaction partner Eps8 [163, 164]. Palladin binds F-actin and crosslinks actin filaments into bundles. It also interacts with Src, thereby affecting Src-mediated actin remodeling [165]. 
Both proteins are also involved in podosome formation which highlights the kinship between DCRs and podosomes [163]. The cancer relevance of Eps8 and palladin is underlined by their increased expression in various human cancers, including breast and thyroid cancer [166-170]. Interestingly, palladin expression appears to be induced by treatment of myofibroblasts with TGF $\beta 1$, suggesting a link between TGF $\beta$ signaling, a major inducer of EMT, and the formation of ruffles and podosomes [171].

\subsection{Lamellipodia and filopodia}

To be able to leave the primary tumor and to disseminate to secondary sites, tumor cells have to break down cell-cell and cell-matrix junctions, as described above, and they have to invade into the surrounding tissue by gaining motility and forming invasive, matrix degrading structures. On planar two-dimensional culture substrates, cells utilize two well-known organelles to explore and move into the surrounding environment, filopodia and lamellipodia. Both are actin-rich membrane protrusions that are formed upon remodeling of the actin cytoskeleton beneath the plasma membrane.

Lamellipodia are flat, sheet-like protrusion and they are the main organelle for cell locomotion. The unbranched, long actin filaments at the base of the lamellipodium are progressing into a highly, lateral branched actin network at the leading edge, giving lamellipodia their typical structure (Fig. 3 b). Here, actin assembly and lateral branching (dendritic nucleation) are mainly controlled by the Arp2/3 complex, a seven subunit protein and major initiator of actin assembly. The activity of the Arp $2 / 3$ complex itself is controlled by actin nucleation-promoting factors, such as the N-WASP or the Scar/WAVE complexes which are themselves recruited to and activated at the membrane by Rac1 [172-174]. Increased expression of Arp2/3 and WAVE2 has been shown to correlate with poor prognosis in breast and liver carcinomas underlining the relevance of lamellipodia-like structures in cancer progression [175, 176]. Furthermore, the formation of lamellipodia is also observed upon ErbB2-driven EMT in epithelial cells, indicating that the formation of lamellipodia-like structures underlies the increased invasiveness observed during EMT [177].

Lamellipodia interact and attach to their environment via different adhesion molecules, including integrins and cadherins $[84,178]$. Also, CD44, the hyaluronan receptor was identified to be in a complex with the protease MT1MMP in lamellipodial protrusions [179]. Here, MT1-MMP binds directly to CD44 and mediates its proteolytic cleavage, thereby stimulating migration (Fig. 3 b).

In contrast, filopodia are rod-like extension consisting of tight bundled actin fibers which penetrate into the surrounding environment originating from the basis of lamellipodia. Filopodia can be considered as a sensory organ of the cell that are used to detect and assimilate signals like chemoattractants or nutrients released from e.g. blood vessels. Interestingly, metastatic cells are rich in filopodia-like structures, which correlates with their invasiveness $[180,181]$. Filopodia formation is based on nonbranched, processive actin assembly, controlled by fascin, diaphanous and Ena/VASP [173, 182] (Fig. 3 b). Actin bundling via fascin, diaphanous and Ena/VASP, on the other hand, is controlled by $\mathrm{Rac}$ and $\mathrm{Cdc} 42$. Fascin upregulation correlates with poor prognosis in different cancer types, including gastric cancer, lung cancer and breast cancer [183-185]. Notably, fascin is a direct target the $\beta$-catenin/Tcf signaling pathway, which is active in the process of EMT as well [71]. Recently, it has been reported that filopodia can transform into lamellipodia by initiating dendritic actin nucleation, characteristic for lamellipodia formation, demonstrating that both filopodia and lamellipodia are highly interactive, inter-convertible structures [186].

\subsection{Podosomes and invadopodia}

To move into or through a three-dimensional matrix, the real life situation, cells have to gain the capability to remodel the ECM via the expression of proteinases. In the last few years, actin-rich protrusion with ECM proteolytic activity, called invadopodia, have drawn particular attention in the context of cancer cell invasion. Invadopodia are considered the transformed counterparts of podosomes, which are formed by non-transformed yet highly migratory cells, such as macrophages, dendritic cells, osteoclasts, and activated smooth muscle and endothelial cells. The exact functions of podosomes are still rather elusive, yet it seems that they are formed when cell adhesion junctions and matrix needs to be concomitantly degraded. This may be the case, when immune cells like monocytes or dendritic cells have to cross tissue boundaries or during bone resorption by osteoclasts for the control of bone homeostasis [187]. The similarities or non-similarities of podosomes and invadopodia are still under debate, yet the most striking differences between both lies in the degree of ECM degradation and their half-lives. Invadopodia are strong degraders of ECM and persist for up to one $h$, whereas podosomes exhibit less ECM degradation activity and are stable only for minutes. Common for invadopodia and podosomes is their architecture. They share an actin filament-rich core containing the actin assembly machinery (WASP, cortactin and Arp2/3) and a multimeric protein complex surrounding the actin core, consisting of integrins and integrin-associated proteins like vinculin, talin and paxillin (Fig. 3 a). The multimeric adhesive ring complex is 


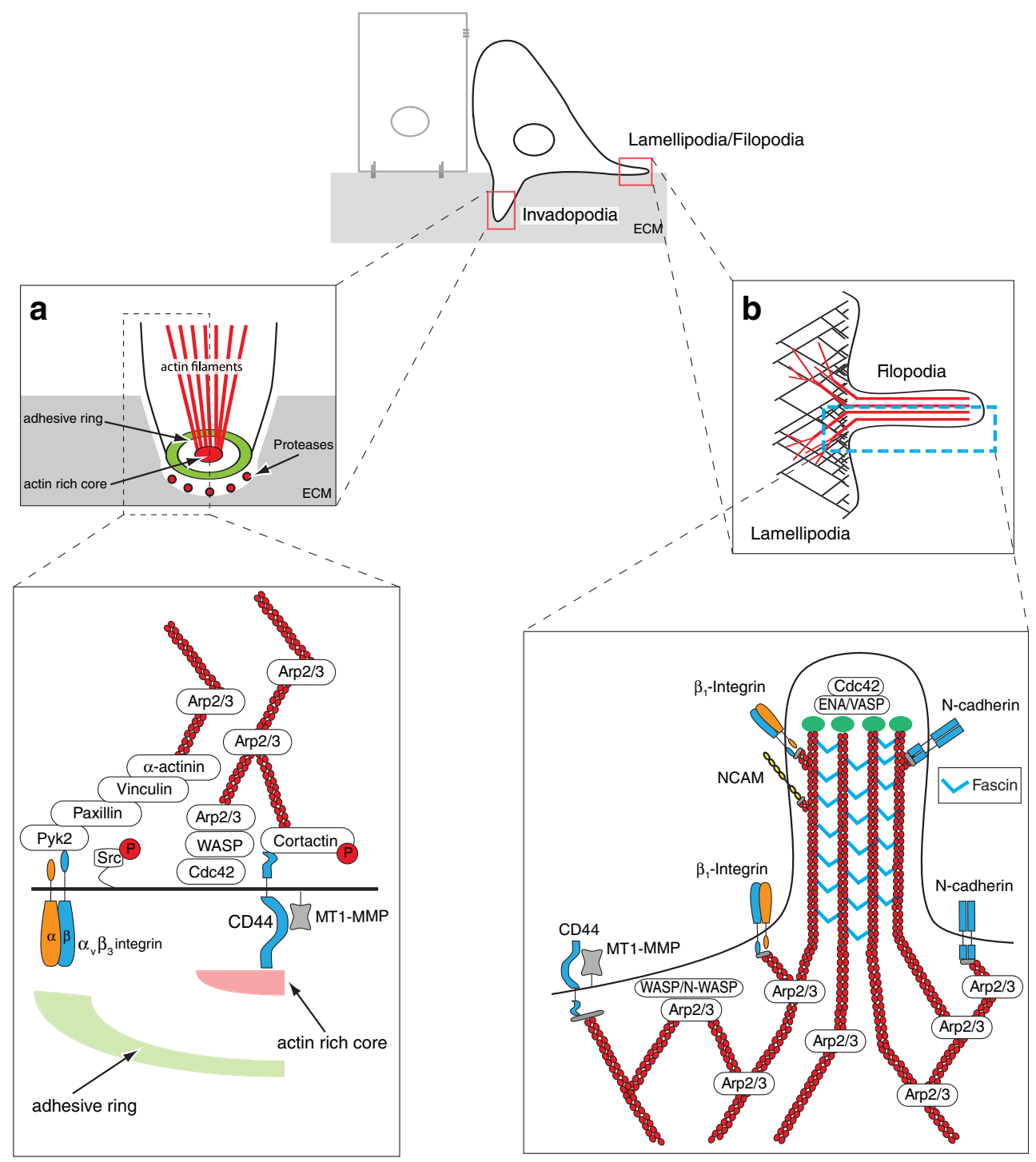

Fig. 3 Upon completion of EMT, spindle-shaped, invasive cells migrate and invade into the surrounding environment by utilizing (i) membrane protrusion like lamellipodia and filopodia for horizontal cell movement and (ii) podosome-derived invasive structures, invadopodia, for ventral invasion. a Invadopodia-mediated invasion. Invadopodia are actin and phosphotyrosine-rich membrane protrusions with a high extracellular matrix degrading capacity. Invadopodia consist of an outer adhesive ring and a central actin-rich core. The non-receptor tyrosine kinase Src, the actin binding protein cortactin and the membrane bound matrix metalloproteinase MT1-MMP play an essential role in the formation and function of invadopodia. Integrins (like $\alpha_{v} \beta_{3}$-integrin), along with their cytoplasmic interaction partners, are positioned in the adhesive ring where they mediate adhesion. The actin organization and nucleation is controlled by the Arp2/3 protein complex (adapted from Block et al. [191]). b

connected to the actin core via radial actin filaments [188191].

Invadopodia of invading tumors cells mediate proteolysis of the ECM via the expression of different MMP, the most prominent being MT1-MMP collagenase and one of its direct targets, MMP2 gelatinase [192]. Invadopodia have
Lamellipodia/filopodia-mediated migration. Lamellipodia are the major organelles for cell movement and build upon highly branched dendritic actin networks, which are initiated by the nucleation promoting factors WASP/N-WASP and the Arp2/3 complex. Lamellipodia interact with their environment via $\mathrm{N}$-cadherin, $\beta_{1}$-integrin or the hyaluronan receptor CD44, the latter also important for the correct positioning of the membrane-bound MT1-MMP. Filopodia are stiff, rod-like extension formed by tightly bundled actin filaments. They function as sensory organs of cells that penetrate into the surrounding microenvironment. They originate from the root of lamellipodia and are initiated and controlled by the concerted activity of the RhoGTPase Cdc42 and nucleation-promoting factor ENA/VASP. The major determinant for actin bundling and filopodia morphology is fascin. Filopodia interact with their environment via the cell adhesion molecules N-cadherin, NCAM, and $\beta_{1}$-integrins

been identified in numerous cancer cell lines, including malignant melanoma, breast cancer, glioma, and head and neck cancer [193-196]. The formation of invadopodia can be initiated by various signals, for example by EGF, HGF or TGF $\beta$-induced signal transduction $[193,197,198]$ or by $\alpha_{6} \beta_{1}$-integrin engagement [199]. Invadopodia-inducing 
growth factors are not only produced by cancer cells themselves but are frequently supplied by tumor-associated macrophages (TAM), which themselves are attracted to the tumor microenvironment by tumor-released chemokines, such as colony stimulating factor 1 (CSF-1) or placental growth factor (PlGF). TAM are well-known to increase cancer cell invasion for example by inducing EGF driven invadopodia formation in the cancer cells $[200,201]$. Besides their important role in primary tumor invasion and tumor cell intravasation into the blood or the lymphatic circulation, invadopodia are also critical for extravasation at secondary sites. Thereby, the chemokines S100A8 and S100A9, produced by endothelial or myeloid cells at the premetastatic niche, attract circulating tumor cells and facilitate their extravasation and invasion at the secondary site by inducing the formation of tumor cell invadopodia [202].

The formation of invadopodia follows distinct steps [194]. First, a local enrichment of actin and cortactin at sites of cell-ECM contact initiates the recruitment of MT1-MMP. This stage is named the pre-invadopodia stage and is then followed by further recruitment of actin, cortactin and MT1-MMP, which leads to matrix degradation and the formation of mature, invading invadopodia. Late invadopodia are defined by dispersal of actin and cortactin leaving an MT1-MMP enriched structure that maintains matrix degradation. A recent report proposes important roles for the calcium-dependent protease calpain-2, protein tyrosine phosphatase PTP1B, and Src for the onset of invadopodia formation and the regulation of invadopodia turnover [203]. Apparently, activation of integrins and/or EGF receptor leads to increased calpain-2 activity, which subsequently proteolytically processes and activates PTP1B. Activated PTP1B wields dephosphorylation of an inhibitory phosphotyrosine of Src resulting in increased Src tyrosine kinase activity, Src-mediated phosphorylation of cortactin and, subsequently, to actin assembly. Conversely, activated Src phosphorylates calpain-2, resulting in proteolytic cleavage and inactivation of cortactin and, thus, invadopodia disassembly. Both Src and cortactin are essential for invadopodia formation and their increased activity can be used as a potential marker for the onset of invadopodia formation [204, 205]. Downstream targets of activated Src which are known to be essential for invadopodia formation and maintenance include cortactin, N-WASP, ArfGAPs like AMAP1/AMAP2, paxillin and Tks5/Fish [197, 206-209].

Invadopodia are known to be enriched with integrins of the $\beta_{1}$-integrin family $\left(\alpha_{3}, \alpha_{5}, \alpha_{6}\right)$ or with $\alpha_{v} \beta_{3}$-integrin [207, 210, 211]. $\beta_{1}$-integrins are receptors for laminin, collagen and fibronectin, $\alpha_{\mathrm{v}} \beta_{3}$-integrins preferentially bind to vitronectin. Furthermore, the interaction of $\alpha_{v} \beta_{3}$-integrin with MT1-MMP leads to the activation of immature MMP2, thereby promoting collagen proteolysis in invasive breast carcinomas [211]. Each of both proteins, $\alpha_{\mathrm{v}} \beta_{3^{-}}$ integrin as well as MT1-MMP, have been shown to be important for EMT $[122,212]$. The co-expression and most likely co-operation of MT1-MMP and $\beta_{1}$-integrin in EMTdriven invasiveness, under the control of the transcription factor Twist, suggests that proteins relevant for invadopodia formation are important for EMT as well [213].

Besides their function as mechanical anchors in the ECM, integrins actively participate in invadopodia formation. For example, engaged $\alpha_{6} \beta_{1}$-integrin induces phosphorylation of p190RhoGAP and promotes its localization in invadopodia, where it represses RhoA activity and supports the formation of membrane protrusions [214]. As key regulators of actin assembly, the major RhoGTPases RhoA, Rac1, and Cdc42 play essential roles in invadopodia formation. Elimination of the activities of Rac1 or Cdc42 results in a reduction of invadopodia formation in glioma cells and mammary carcinoma cells, respectively [197, 215]. On the other hand, RhoA is known to be important for actin assembly and exocytosis of MMP in invadopodia by controlling IQGAP1 activity [216]. For more detailed insights into invadopodia formation and function, we refer the reader to several excellent recent reviews [188, 217219].

7.5 Lamellipodia, filopodia and their overlap with invadopodia

The kinship between the two-dimensional filopodia and lamellipodia with three-dimensional invadopodia is still under debate. It seems that invadopodia represent a hybrid of both structures. Like lamellipodia, invadopodia are built upon a branched actin network, yet they employ N-WASP for actin assembly instead of WAVE-2 used by lamellipodia. On the other hand, both invadopodia and filopodia engage $\mathrm{Cdc} 42$ for the induction of membrane protrusions which are long and thin in their appearance, suggesting that actin bundling could play an important role in invadopodia formation. However, whether filopodial actin-bundling proteins like fascin are located in invadopodia remains to be determined [220].

\subsection{Invadopodia and their role in EMT}

As illustrated above, EMT leads to increased motility and invasiveness of epithelial cells by dissolving epithelial cellcell adhesion, modulating cell-matrix adhesion and by inducing the secretion of ECM degrading proteinases. Thus, it can be assumed that EMT provokes the formation of podosome or invadopodia-like structures. Surprisingly, up to date there is no experimental evidence that directly links EMT with the formation of invadopodia or podosomes. Nonetheless, a number of proteins that are important 
for invadopodia formation and for the execution of EMT have been identified, strongly suggesting that invadopodia formation could be involved in EMT-driven cell invasion. Both EMT and invadopodia formation can be stimulated by various growth factors, including EGF, HGF, PDGF, and $\operatorname{TGF} \beta[5,197,221]$. The engagement of these growth factors leads to the activation of the non-receptor tyrosine kinase Src. The potency of Src to induce EMT and/or invadopodia formation is well established [203, 205, 222]. Moreover, downstream targets of Src-signaling, such as calpain, are upregulated during TGF $\beta$-induced EMT and are required for invadopodia formation [203, 223]. Another protein, able to induce invadopodia and also involved in EMT, is endoglin, a cell surface adhesion molecule and coreceptor for TGF $\beta$ signaling [224]. Endoglin is needed for EMT during heart development, and its expression correlates with increased invasiveness of breast cancer cells via the increased formation of invadopodia [198, 225].

Most likely, invadopodia and podosomes are not only matrix degrading structures but also function as guidance organelles that provide a cell with the ability to probe its microenvironment by exploring potential cell-cell and cellmatrix adhesions and by sensing chemoattractive cues. Interestingly, PDGF induces the translocation of cortactin to podosomes via the GAP BPGAP1 and Rac1, indicating that PDGF receptor is involved in the formation of podosomes $[226,227]$. As described above, PDGFR colocalizes with $\mathrm{N}$-cadherin in membrane ruffles, and both $\mathrm{N}$-cadherin and cortactin are found in the growth cones of emerging neuronal axons and exert a crucial role in neuron guidance $[81,228]$. The co-localization of cortactin with the Ncadherin/NCAM/FGFR complex and NCAM-mediated FGFR signaling have been shown to contribute to neurite outgrowth [95]. Thus, consistent with its upregulated expression during EMT (the cadherin switch, see above), $\mathrm{N}$-cadherin is likely to be involved in the formation of invadopodia.

\section{Outlook}

In this review, we have attempted to summarize recent novel insights into the functional contribution of cellular processes, such as the formation of membrane protrusions and the reorganization of the actin cytoskeleton to EMT and tumor metastasis. While there is an increasing functional correlation between the formation of migratory and invasive membrane protrusions and the process of EMT, a direct link between the cellular and molecular processes underlying the formation of lamellipodia, filopodia and invadopodia on one hand, and EMT and tumor metastasis on the other hand, still remains to be established. Apparently, if such link can be ascertained, the molecular mechanisms and genes and factors underlying the cellular organization of the cytoskeleton and the formation of membrane protrusions move into the spotlight of medical relevance, i.e. the design and development of innovative therapeutic approaches to interfere with cancer cell invasion and metastatic dissemination. Hence, future research to resolve these issues is urgently warranted.

Acknowledgements We apologize to all colleagues whose important work we could not cite due to space restrictions. Research in the laboratory of the authors has been supported by the EU-FP6 framework program BRECOSM LSHC-CT-2004-503224, the EUFP7 framework program TUMIC 2008-201662, the NCCR Molecular Oncology of the Swiss National Science Foundation, the Swiss Cancer League, and the Krebsliga Beider Basel.

\section{References}

1. Thiery, J. P., \& Sleeman, J. P. (2006). Complex networks orchestrate epithelial-mesenchymal transitions. Nat Rev Mol Cell Biol, 7, 131-142.

2. Grunert, S., Jechlinger, M., \& Beug, H. (2003). Diverse cellular and molecular mechanisms contribute to epithelial plasticity and metastasis. Nat Rev Mol Cell Biol, 4, 657-665.

3. Zavadil, J., \& Bottinger, E. P. (2005). TGF-beta and epithelial-tomesenchymal transitions. Oncogene, 24, 5764-5774.

4. Savagner, P., Yamada, K. M., \& Thiery, J. P. (1997). The zincfinger protein slug causes desmosome dissociation, an initial and necessary step for growth factor-induced epithelial-mesenchymal transition. J Cell Biol, 137, 1403-1419.

5. Lo, H. W., Hsu, S. C., Xia, W., Cao, X., Shih, J. Y., \& Wei, Y. (2007). Epidermal growth factor receptor cooperates with signal transducer and activator of transcription 3 to induce epithelialmesenchymal transition in cancer cells via up-regulation of TWIST gene expression. Cancer Res, 67, 9066-9076.

6. Graham, T. R., Zhau, H. E., Odero-Marah, V. A., Osunkoya, A. O., Kimbro, K. S., \& Tighiouart, M. (2008). Insulin-like growth factorI-dependent up-regulation of ZEB1 drives epithelial-to-mesenchymal transition in human prostate cancer cells. Cancer Res, 68, 2479-2488.

7. Lee, J. M., Dedhar, S., Kalluri, R., \& Thompson, E. W. (2006). The epithelial-mesenchymal transition: new insights in signaling, development, and disease. J Cell Biol, 172(7), 973-981.

8. Acevedo, V. D., Gangula, R. D., Freeman, K. W., Li, R., Zhang, Y., \& Wang, F. (2007). Inducible FGFR-1 activation leads to irreversible prostate adenocarcinoma and an epithelial-to-mesenchymal transition. Cancer Cell, 12, 559-571.

9. Leong, K. G., Niessen, K., Kulic, I., Raouf, A., Eaves, C., \& Pollet, I. (2007). Jagged1-mediated Notch activation induces epithelial-to-mesenchymal transition through Slug-induced repression of E-cadherin. J Exp Med, 204, 2935-2948.

10. Shintani, Y., Maeda, M., Chaika, N., Johnson, K. R., \& Wheelock, M. J. (2008). Collagen I promotes epithelial-to-mesenchymal transition in lung cancer cells via transforming growth factor-beta signaling. Am J Respir Cell Mol Biol, 38, 95-104.

11. Zoltan-Jones, A., Huang, L., Ghatak, S., \& Toole, B. P. (2003). Elevated hyaluronan production induces mesenchymal and transformed properties in epithelial cells. J Biol Chem, 278, 45801-45810.

12. Bhowmick, N. A., Ghiassi, M., Bakin, A., Aakre, M., Lundquist, C. A., \& Engel, M. E. (2001). Transforming growth factor-beta1 
mediates epithelial to mesenchymal transdifferentiation through a RhoA-dependent mechanism. Mol Biol Cell, 12, 27-36.

13. Bakin, A. V., Rinehart, C., Tomlinson, A. K., \& Arteaga, C. L. (2002). p38 mitogen-activated protein kinase is required for TGFbeta-mediated fibroblastic transdifferentiation and cell migration. J Cell Sci, 115, 3193-3206.

14. Janda, E., Lehmann, K., Killisch, I., Jechlinger, M., Herzig, M., \& Downward, J. (2002). Ras and TGF[beta] cooperatively regulate epithelial cell plasticity and metastasis: dissection of Ras signaling pathways. J Cell Biol, 156, 299-313.

15. Bakin, A. V., Tomlinson, A. K., Bhowmick, N. A., Moses, H. L., \& Arteaga, C. L. (2000). Phosphatidylinositol 3-kinase function is required for transforming growth factor beta-mediated epithelial to mesenchymal transition and cell migration. $J$ Biol Chem, 275, 36803-36810.

16. Lee, Y. I., Kwon, Y. J., \& Joo, C. K. (2004). Integrin-linked kinase function is required for transforming growth factor betamediated epithelial to mesenchymal transition. Biochem Biophys Res Commun, 316, 997-1001.

17. Zavadil, J., Cermak, L., Soto-Nieves, N., \& Bottinger, E. P. (2004). Integration of TGF-beta/Smad and Jagged1/Notch signalling in epithelial-to-mesenchymal transition. EMBO J,23, 1155-1165.

18. Gregory, P. A., Bert, A. G., Paterson, E. L., Barry, S. C., Tsykin, A., \& Farshid, G. (2008). The miR-200 family and miR-205 regulate epithelial to mesenchymal transition by targeting ZEB1 and SIP1. Nat Cell Biol, 10, 593-601.

19. Sarrio, D., Rodriguez-Pinilla, S. M., Hardisson, D., Cano, A., Moreno-Bueno, G., \& Palacios, J. (2008). Epithelial-mesenchymal transition in breast cancer relates to the basal-like phenotype. Cancer Res, 68, 989-997.

20. Brabletz, T., Hlubek, F., Spaderna, S., Schmalhofer, O., Hiendlmeyer, E., \& Jung, A. (2005). Invasion and metastasis in colorectal cancer: epithelial-mesenchymal transition, mesenchymal-epithelial transition, stem cells and beta-catenin. Cells Tissues Organs, 179(1-2), 56-65.

21. Tarin, D., Thompson, E. W., \& Newgreen, D. F. (2005). The fallacy of epithelial mesenchymal transition in neoplasia. Cancer Res, 65, 5996-6000 discussion 6000-1.

22. Friedl, P. (2004). Prespecification and plasticity: shifting mechanisms of cell migration. Curr Opin Cell Biol, 16, 14-23.

23. Wicki, A., Lehembre, F., Wick, N., Hantusch, B., Kerjaschki, D., \& Christofori, G. (2006). Tumor invasion in the absence of epithelial-mesenchymal transition: podoplanin-mediated remodeling of the actin cytoskeleton. Cancer Cell, 9, 261-272.

24. Yamada, S., Pokutta, S., Drees, F., Weis, W. I., \& Nelson, W. J. (2005). Deconstructing the cadherin-catenin-actin complex. Cell, 123, 889-901.

25. Cavey, M., Rauzi, M., Lenne, P. F., \& Lecuit, T. (2008). A twotiered mechanism for stabilization and immobilization of Ecadherin. Nature, 453, 751-756.

26. Abe, K., \& Takeichi, M. (2008). EPLIN mediates linkage of the cadherin catenin complex to F-actin and stabilizes the circumferential actin belt. Proc Natl Acad Sci U S A, 105, 13-19.

27. Stehbens, S. J., Paterson, A. D., Crampton, M. S., Shewan, A. M., Ferguson, C., Akhmanova, A., et al. (2006). Dynamic microtubules regulate the local concentration of E-cadherin at cell-cell contacts. J Cell Sci, 119(Pt 9), 1801-1811.

28. Ireton, R. C., Davis, M. A., van Hengel, J., Mariner, D. J., Barnes, K., \& Thoreson, M. A. (2002). A novel role for p120 catenin in E-cadherin function. $J$ Cell Biol, 159(3), 465-476.

29. Davis, M. A., Ireton, R. C., \& Reynolds, A. B. (2003). A core function for p120-catenin in cadherin turnover. J Cell Biol, 163, $525-534$.

30. Thoreson, M. A., Anastasiadis, P. Z., Daniel, J. M., Ireton, R. C., Wheelock, M. J., Johnson, K. R., et al. (2000). Selective uncoupling of p120(ctn) from E-cadherin disrupts strong adhesion. J Cell Biol, 148(1), 189-202.

31. Wildenberg, G. A., Dohn, M. R., Carnahan, R. H., Davis, M. A., Lobdell, N. A., Settleman, J., et al. (2006). p120-catenin and p190RhoGAP regulate cell-cell adhesion by coordinating antagonism between Rac and Rho. Cell, 127, 1027-1039.

32. Noren, N. K., Niessen, C. M., Gumbiner, B. M., \& Burridge, K. (2001). Cadherin engagement regulates Rho family GTPases. $J$ Biol Chem, 276, 33305-33308.

33. Noren, N. K., Liu, B. P., Burridge, K., \& Kreft, B. (2000). p120 catenin regulates the actin cytoskeleton via Rho family GTPases. $J$ Cell Biol, 150, 567-580.

34. Comoglio, P. M., Boccaccio, C., \& Trusolino, L. (2003). Interactions between growth factor receptors and adhesion molecules: breaking the rules. Curr Opin Cell Biol, 15, 565-571.

35. Chattopadhyay, N., Wang, Z., Ashman, L. K., Brady-Kalnay, S. M., \& Kreidberg, J. A. (2003). alpha3beta1 integrin-CD151, a component of the cadherin-catenin complex, regulates PTPmu expression and cell-cell adhesion. J Cell Biol, 163, 1351-1362.

36. Vasioukhin, V., Baue, C., Yin, M., \& Fuchs, E. (2000). Directed actin polymerization is the driving force for epithelial cell-cell adhesion. Cell, 100, 209-219.

37. Shigeta, M., Sanzen, N., Ozawa, M., Gu, J., Hasegawa, H., \& Sekiguchi, K. (2003). CD151 regulates epithelial cell-cell adhesion through PKC- and Cdc42-dependent actin cytoskeletal reorganization. J Cell Biol, 163, 165-176.

38. Helwani, F. M., Kovacs, E. M., Paterson, A. D., Verma, S., Ali, R. G., \& Fanning, A. S. (2004). Cortactin is necessary for Ecadherin-mediated contact formation and actin reorganization. $J$ Cell Biol, 164, 899-910.

39. Canonici, A., Steelant, W., Rigot, V., Khomitch-Baud, A., Boutaghou-Cherid, H., Bruyneel, E., et al. (2008). Insulin-like growth factor-I receptor, E-cadherin and alpha $\mathrm{v}$ integrin form a dynamic complex under the control of alpha-catenin. Int $J$ Cancer, 122, 572-582.

40. Reshetnikova, G., Troyanovsky, S., \& Rimm, D. L. (2007). Definition of a direct extracellular interaction between Met and E-cadherin. Cell Biol Int, 31, 366-373.

41. Bissell, M. J., \& Radisky, D. (2001). Putting tumours in context. Nat Rev Cancer, 1, 46-54.

42. Cavallaro, U., \& Christofori, G. (2004). Cell adhesion and signalling by cadherins and Ig-CAMs in cancer. Nat Rev Cancer, 4, 118-132.

43. Perl, A. K., Wilgenbus, P., Dahl, U., Semb, H., \& Christofori, G. (1998). A causal role for E-cadherin in the transition from adenoma to carcinoma. Nature, 392, 190-193.

44. Peinado, H., Olmeda, D., \& Cano, A. (2007). Snail, Zeb and bHLH factors in tumour progression: an alliance against the epithelial phenotype? Nat Rev Cancer, 7, 415-428.

45. Kouzarides, T. (2007). Chromatin modifications and their function. Cell, 128, 693-705.

46. Jenuwein, T., \& Allis, C. D. (2001). Translating the histone code. Science, 293, 1074-1080.

47. Zhang, Y., \& Reinberg, D. (2001). Transcription regulation by histone methylation: interplay between different covalent modifications of the core histone tails. Genes Dev, 15, 2343-2360.

48. Herranz, N., Pasini, D., Diaz, V. M., Franci, C., Gutierrez, A., \& Dave, N. (2008). Polycomb complex 2 is required for E-cadherin repression by the Snaill transcription factor. Mol Cell Biol, 28 (15), 4772-4781.

49. Hou, Z., Peng, H., Ayyanathan, K., Yan, K. P., Langer, E. M., \& Longmore, G. D. (2008). The LIM protein AJUBA recruits protein arginine methyltransferase 5 to mediate SNAIL-dependent transcriptional repression. Mol Cell Biol, 28, 3198-3207.

50. Berger, S. L. (2007). The complex language of chromatin regulation during transcription. Nature, 447, 407-412. 
51. Zhu, W., Leber, B., \& Andrews, D. W. (2001). Cytoplasmic Oglycosylation prevents cell surface transport of E-cadherin during apoptosis. EMBO J, 20, 5999-6007.

52. Lochter, A., Galosy, S., Muschler, J., Freedman, N., Werb, Z., \& Bissell, M. J. (1997). Matrix metalloproteinase stromelysin-1 triggers a cascade of molecular alterations that leads to stable epithelial-to-mesenchymal conversion and a premalignant phenotype in mammary epithelial cells. $J$ Cell Biol, 139, 1861-1872.

53. Marambaud, P., Shioi, J., Serban, G., Georgakopoulos, A., Sarner, S., \& Nagy, V. (2002). A presenilin-1/gamma-secretase cleavage releases the E-cadherin intracellular domain and regulates disassembly of adherens junctions. EMBO J, 21, 1948-1956.

54. Maretzky, T., Reiss, K., Ludwig, A., Buchholz, J., Scholz, F., \& Proksch, E. (2005). ADAM10 mediates E-cadherin shedding and regulates epithelial cell-cell adhesion, migration, and beta-catenin translocation. Proc Natl Acad Sci U S A, 102, 9182-9187.

55. Steinhusen, U., Weiske, J., Badock, V., Tauber, R., Bommert, K., \& Huber, O. (2001). Cleavage and shedding of E-cadherin after induction of apoptosis. $J$ Biol Chem, 276, 4972-4980.

56. Ferber, E. C., Kajita, M., Wadlow, A., Tobiansky, L., Niessen, C., \& Ariga, H. (2008). A role for the cleaved cytoplasmic domain of Ecadherin in the nucleus. $J$ Biol Chem, 283, 12691-12700.

57. Gumbiner, B. M. (2000). Regulation of cadherin adhesive activity. J Cell Biol, 148, 399-404.

58. Fujita, Y., Krause, G., Scheffner, M., Zechner, D., Leddy, H. E., \& Behrens, J. (2002). Hakai, a c-Cbl-like protein, ubiquitinates and induces endocytosis of the E-cadherin complex. Nat Cell Biol, 4, 222-231.

59. Koenig, A., Mueller, C., Hasel, C., Adler, G., \& Menke, A. (2006). Collagen type I induces disruption of E-cadherinmediated cell-cell contacts and promotes proliferation of pancreatic carcinoma cells. Cancer Res, 66, 4662-4671.

60. Janda, E., Nevolo, M., Lehmann, K., Downward, J., Beug, H., \& Grieco, M. (2006). Raf plus TGFbeta-dependent EMT is initiated by endocytosis and lysosomal degradation of E-cadherin. Oncogene, 25, 7117-7130.

61. Lu, Z., Ghosh, S., Wang, Z., \& Hunter, T. (2003). Downregulation of caveolin-1 function by EGF leads to the loss of Ecadherin, increased transcriptional activity of beta-catenin, and enhanced tumor cell invasion. Cancer Cell, 4, 499-515.

62. Akhtar, N., \& Hotchin, N. A. (2001). RAC1 regulates adherens junctions through endocytosis of E-cadherin. Mol Biol Cell, 12, 847-862.

63. Steeg, P. S., Bevilacqua, G., Kopper, L., Thorgeirsson, U. P., Talmadge, J. E., \& Liotta, L. A. (1988). Evidence for a novel gene associated with low tumor metastatic potential. $J$ Natl Cancer Inst, 80, 200-204.

64. Palacios, F., Schweitzer, J. K., Boshans, R. L., D, , \& SouzaSchorey, C. (2002). ARF6-GTP recruits Nm23-H1 to facilitate dynamin-mediated endocytosis during adherens junctions disassembly. Nat Cell Biol, 4, 929-936.

65. Kon, S., Tanabe, K., Watanabe, T., Sabe, H., \& Satake, M. (2008). Clathrin dependent endocytosis of E-cadherin is regulated by the Arf6GAP isoform SMAP1. Exp Cell Res, 314, 1415-1428.

66. Tanabe, K., Torii, T., Natsume, W., Braesch-Andersen, S., Watanabe, T., \& Satake, M. (2005). A novel GTPase-activating protein for ARF6 directly interacts with clathrin and regulates clathrin-dependent endocytosis. Mol Biol Cell, 16, 1617-1628.

67. Clevers, H. (2006). Wnt/beta-catenin signaling in development and disease. Cell, 127, 469-480.

68. Arce, L., Yokoyama, N. N., \& Waterman, M. L. (2006). Diversity of LEF/TCF action in development and disease. Oncogene, 25, 7492-7504

69. Wong, N. A., \& Pignatelli, M. (2002). Beta-catenin-a linchpin in colorectal carcinogenesis? Am J Pathol, 160, 389-401.
70. Vignjevic, D., Kojima, S., Aratyn, Y., Danciu, O., Svitkina, T., \& Borisy, G. G. (2006). Role of fascin in filopodial protrusion. $J$ Cell Biol, 174, 863-875.

71. Vignjevic, D., Schoumacher, M., Gavert, N., Janssen, K. P., Jih, G., \& Lae, M. (2007). Fascin, a novel target of beta-catenin-TCF signaling, is expressed at the invasive front of human colon cancer. Cancer Res, 67, 6844-6853.

72. van, Roy, F. M., \& McCrea, P. D. (2005). A role for Kaisop120ctn complexes in cancer? Nat Rev Cancer, 5, 956-964.

73. Nieman, M. T., Prudoff, R. S., Johnson, K. R., \& Wheelock, M. J. (1999). N-cadherin promotes motility in human breast cancer cells regardless of their E-cadherin expression. J Cell Biol, 147, 631-644.

74. Hulit, J., Suyama, K., Chung, S., Keren, R., Agiostratidou, G., Shan, W., \& Dong, X. (2007). N-cadherin signaling potentiates mammary tumor metastasis via enhanced extracellular signalregulated kinase activation. Cancer Res, 67, 3106-3116.

75. Gravdal, K., Halvorsen, O. J., Haukaas, S. A., \& Akslen, L. A. (2007). A switch from E-cadherin to N-cadherin expression indicates epithelial to mesenchymal transition and is of strong and independent iportance for the progress of prostate cancer. Clin Cancer Res, 13, 7003-7011.

76. Hazan, R. B., Qiao, R., Keren, R., Badano, I., \& Suyama, K. (2004). Cadherin switch in tumor progression. Ann N Y Acad Sci, 1014, 155-163.

77. Shintani, Y., Fukumoto, Y., Chaika, N., Svoboda, R., Wheelock, M. J., \& Johnson, K. R. (2008). Collagen I-mediated upregulation of $\mathrm{N}$-cadherin requires cooperative signals from integrins and discoidin domain receptor 1. J Cell Biol, 180, $1277-1289$.

78. Alexander, N. R., Tran, N. L., Rekapally, H., Summers, C. E., Glackin, C., \& Heimark, R. L. (2006). N-cadherin gene expression in prostate carcinoma is modulated by integrindependent nuclear translocation of Twist1. Cancer Res, 66, 3365-3369.

79. Yang, Z., Zhang, X., Gang, H., Li, X., Li, Z., \& Wang, T. (2007). Up-regulation of gastric cancer cell invasion by Twist is accompanied by N-cadherin and fibronectin expression. Biochem Biophys Res Commun, 358, 925-930.

80. Niu, R. F., Zhang, L., Xi, G. M., Wei, X. Y., Yang, Y., \& Shi, Y. R. (2007). Up-regulation of Twist induces angiogenesis and correlates with metastasis in hepatocellular carcinoma. J Exp Clin Cancer Res, 26, 385-394.

81. Bard, L., Boscher, C., Lambert, M., Mege, R. M., Choquet, D., \& Thoumine, O. (2008). A molecular clutch between the actin flow and $\mathrm{N}$-cadherin adhesions drives growth cone migration. $J$ Neurosci, 28, 5879-5890.

82. El, Sayegh, T. Y., Arora, P. D., Fan, L., Laschinger, C. A., Greer, P. A., \& McCulloch, C. A. (2005). Phosphorylation of Ncadherin-associated cortactin by Fer kinase regulates N-cadherin mobility and intercellular adhesion strength. Mol Biol Cell, 16, $5514-5527$.

83. Kim, L., \& Wong, T. W. (1995). The cytoplasmic tyrosine kinase FER is associated with the catenin-like substrate pp120 and is activated by growth factors. Mol Cell Biol, 15, 4553-4561.

84. Comunale, F., Causeret, M., Favard, C., Cau, J., Taulet, N., \& Charrasse, S. (2007). Rac1 and RhoA GTPases have antagonistic functions during $\mathrm{N}$-cadherin-dependent cell-cell contact formation in C2C12 myoblasts. Biol Cell, 99, 503-517.

85. Xu, G., Craig, A. W., Greer, P., Miller, M., Anastasiadis, P. Z., \& Lilien, J. (2004). Continuous association of cadherin with betacatenin requires the non-receptor tyrosine-kinase Fer. $J$ Cell Sci, 117, 3207-3219.

86. Xu, G., Arregui, C., Lilien, J., \& Balsamo, J. (2002). PTP1B modulates the association of beta-catenin with $\mathrm{N}$-cadherin through binding to an adjacent and partially overlapping target site. J Biol Chem, 277, 49989-49997. 
87. Theisen, C. S., Wahl 3rd, J. K., Johnson, K. R., \& Wheelock, M. J. (2007). NHERF links the N-cadherin/catenin complex to the platelet-derived growth factor receptor to modulate the actin cytoskeleton and regulate cell motility. Mol Biol Cell, 18, 12201232.

88. Heldin, C. H., Ostman, A., \& Ronnstrand, L. (1998). Signal transduction via platelet-derived growth factor receptors. Biochim Biophys Acta, 1378, F79-113.

89. Kong, D., Wang, Z., Sarkar, S. H., Li, Y., Banerjee, S., \& Saliganan, A. (2008). Platelet-derived growth factor-D overexpression contributes to epithelial-mesenchymal transition of PC3 prostate cancer cells. Stem Cells, 26, 1425-1435.

90. Sander, E. E., ten Klooster, J. P., van Delft, S., van der Kammen, R. A., \& Collard, J. G. (1999). Rac downregulates Rho activity: reciprocal balance between both GTPases determines cellular morphology and migratory behavior. J Cell Biol, 147, 1009-1022.

91. Pertz, O., Hodgson, L., Klemke, R. L., \& Hahn, K. M. (2006). Spatiotemporal dynamics of RhoA activity in migrating cells. Nature, 440, 1069-1072.

92. Ridley, A. J., Paterson, H. F., Johnston, C. L., Diekmann, D., \& Hall, A. (1992). The small GTP-binding protein rac regulates growth factor-induced membrane ruffling. Cell, 70, 401-410.

93. Nimnual, A. S., Taylor, L. J., \& Bar-Sagi, D. (2003). Redoxdependent downregulation of Rho by Rac. Nat Cell Biol, 5, 236241.

94. Anastasiadis, P. Z., Moon, S. Y., Thoreson, M. A., Mariner, D. J., Crawford, H. C., Zheng, Y., et al. (2000). Inhibition of RhoA by p120 catenin. Nat Cell Biol, 2, 637-644.

95. Cavallaro, U., Niedermeyer, J., Fuxa, M., \& Christofori, G. (2001). N-CAM modulates tumour-cell adhesion to matrix by inducing FGF-receptor signalling. Nat Cell Biol, 3, 650-657.

96. Williams, E. J., Williams, G., Howell, F. V., Skaper, S. D., Walsh, F. S., \& Doherty, P. (2001). Identification of an Ncadherin motif that can interact with the fibroblast growth factor receptor and is required for axonal growth. J Biol Chem, 276, 43879-43886.

97. Hazan, R. B., Phillips, G. R., Qiao, R. F., Norton, L., \& Aaronson, S. A. (2000). Exogenous expression of N-cadherin in breast cancer cells induces cell migration, invasion, and metastasis. J Cell Biol, 148, 779-790.

98. Suyama, K., Shapiro, I., Guttman, M., \& Hazan, R. B. (2002). A signaling pathway leading to metastasis is controlled by N-cadherin and the FGF receptor. Cancer Cell, 2, 301-314.

99. Francavilla, C., Loeffler, S., Piccini, D., Kren, A., Christofori, G., \& Cavallaro, U. (2007). Neural cell adhesion molecule regulates the cellular response to fibroblast growth factor. J Cell Sci, 120, 4388-4394.

100. Sanchez-Heras, E., Howell, F. V., Williams, G., \& Doherty, P. (2006). The fibroblast growth factor receptor acid box is essential for interactions with $\mathrm{N}$-cadherin and all of the major isoforms of neural cell adhesion molecule. J Biol Chem, 281, 35208-35216.

101. Christofori, G. (2006). New signals from the invasive front. Nature, 441, 444-450.

102. Marambaud, P., Wen, P. H., Dutt, A., Shioi, J., Takashima, A., \& Siman, R. (2003). A CBP binding transcriptional repressor produced by the PS1/epsilon-cleavage of N-cadherin is inhibited by PS1 FAD mutations. Cell, 114, 635-645.

103. Shoval, I., Ludwig, A., \& Kalcheim, C. (2007). Antagonistic roles of full-length $\mathrm{N}$-cadherin and its soluble BMP cleavage product in neural crest delamination. Development, 134, 491-501.

104. Uemura, K., Kihara, T., Kuzuya, A., Okawa, K., Nishimoto, T., Bito, H., \& Ninomiya, H. (2006). Activity-dependent regulation of beta-catenin via epsilon-cleavage of N-cadherin. Biochem Biophys Res Commun, 345, 951-958.
105. Tadokoro, S., Shattil, S. J., Eto, K., Tai, V., Liddington, R. C., dePereda, J. M., et al. (2003). Talin binding to integrin beta tails: a final common step in integrin activation. Science, 302, 103-106.

106. Deryugina, E. I., Bourdon, M. A., Jungwirth, K., Smith, J. W., \& Strongin, A. Y. (2000). Functional activation of integrin alpha V beta 3 in tumor cells expressing membrane-type 1 matrix metalloproteinase. Int $J$ Cancer, 86, 15-23.

107. Legate, K. R., Montanez, E., Kudlacek, O., \& Fassler, R. (2006). ILK, PINCH and parvin: the tIPP of integrin signalling. Nat Rev Mol Cell Biol, 7, 20-31.

108. Mercurio, A. M., \& Rabinovitz, I. (2001). Towards a mechanistic understanding of tumor invasion-lessons from the alpha6beta 4 integrin. Semin Cancer Biol, 11, 129-141.

109. Trusolino, L., Bertotti, A., \& Comoglio, P. M. (2001). A signaling adapter function for alpha 6beta 4 integrin in the control of HGF-dependent invasive growth. Cell, 107, 643-654.

110. Mariotti, A., Kedeshian, P. A., Dans, M., Curatola, A. M., Gagnoux-Palacios, L., \& Giancotti, F. G. (2001). EGF-R signaling through Fyn kinase disrupts the function of integrin alpha6beta4 at hemidesmosomes: role in epithelial cell migration and carcinoma invasion. $J$ Cell Biol, 155, 447-458.

111. Gambaletta, D., Marchetti, A., Benedetti, L., Mercurio, A. M., Sacchi, A., \& Falcioni, R. (2000). Cooperative signaling between alpha (6)beta(4) integrin and ErbB-2 receptor is required to promote phosphatidylinositol 3-kinase-dependent invasion. $J$ Biol Chem, 275, 10604-10610.

112. Ivaska, J., Reunanen, H., Westermarck, J., Koivisto, L., Kahari, V. M., \& Heino, J. (1999). Integrin alpha2beta1 mediates isoform-specific activation of $\mathrm{p} 38$ and upregulation of collagen gene transcription by a mechanism involving the alpha2 cytoplasmic tail. J Cell Biol, 147, 401-416.

113. Ellinger-Ziegelbauer, H., Kelly, K., \& Siebenlist, U. (1999). Cell cycle arrest and reversion of Ras-induced transformation by a conditionally activated form of mitogen-activated protein kinase kinase kinase 3. Mol Cell Biol, 19, 3857-3868.

114. Munger, J. S., Huang, X., Kawakatsu, H., Griffiths, M. J., Dalton, S. L., \& Wu, J. (1999). The integrin alpha $\mathrm{v}$ beta 6 binds and activates latent TGF beta 1: a mechanism for regulating pulmonary inflammation and fibrosis. Cell, 96, 319-328.

115. Mu, D., Cambier, S., Fjellbirkeland, L., Baron, J. L., Munger, J. S., \& Kawakatsu, H. (2002). The integrin alpha(v)beta8 mediates epithelial homeostasis through MT1-MMP-dependent activation of TGF-beta1. J Cell Biol, 157, 493-507.

116. Wipff, P. J., \& Hinz, B. (2008). Integrins and the activation of latent transforming growth factor betal-An intimate relationship. Eur J Cell Biol, 87(8-9), 601-615.

117. Haraguchi, M., Okubo, T., Miyashita, Y., Miyamoto, Y., Hayashi, M., \& Crotti, T. N. (2008). Snail regulates cellmatrix adhesion by regulation of the expression of integrins and basement membrane proteins. J Biol Chem, 283(35), 23514-23523.

118. Sharma, M., \& Henderson, B. R. (2007). IQ-domain GTPaseactivating protein 1 regulates beta-catenin at membrane ruffles and its role in macropinocytosis of $\mathrm{N}$-cadherin and adenomatous polyposis coli. $J$ Biol Chem, 282, 8545-8556.

119. Ellerbroek, S. M., Wu, Y. I., Overall, C. M., \& Stack, M. S. (2001). Functional interplay between type I collagen and cell surface matrix metalloproteinase activity. J Biol Chem, 276, 24833-24842.

120. Wolf, K., Muller, R., Borgmann, S., Brocker, E. B., \& Friedl, P. (2003). Amoeboid shape change and contact guidance: Tlymphocyte crawling through fibrillar collagen is independent of matrix remodeling by MMPs and other proteases. Blood, 102, 3262-3269.

121. Cao, J., Chiarelli, C., Richman, O., Zarrabi, K., Kozarekar, P., \& Zucker, S. (2008). Membrane type 1 matrix metalloproteinase 
induces epithelial-to-mesenchymal transition in prostate cancer. $J$ Biol Chem, 283, 6232-6240.

122. Pulyaeva, H., Bueno, J., Polette, M., Birembaut, P., Sato, H., \& Seiki, M. (1997). MT1-MMP correlates with MMP-2 activation potential seen after epithelial to mesenchymal transition in human breast carcinoma cells. Clin Exp Metastasis, 15, 111-120.

123. Bhowmick, N. A., Zent, R., Ghiassi, M., McDonnell, M., \& Moses, H. L. (2001). Integrin beta 1 signaling is necessary for transforming growth factor-beta activation of p38MAPK and epithelial plasticity. $J$ Biol Chem, 276, 46707-46713.

124. Bravo-Cordero, J. J., Marrero-Diaz, R., Megias, D., Genis, L., Garcia-Grande, A., \& Garcia, M. A. (2007). MT1-MMP proinvasive activity is regulated by a novel Rab8-dependent exocytic pathway. EMBO J, 26, 1499-1510.

125. Sheppard, D. (2005). Integrin-mediated activation of latent transforming growth factor beta. Cancer Metastasis Rev, 24, 395-402.

126. Roberts, A. B., \& Wakefield, L. M. (2003). The two faces of transforming growth factor beta in carcinogenesis. Proc Natl Acad Sci U S A, 100, 8621-8623.

127. Bates, R. C. (2005). Colorectal cancer progression: integrin alphavbeta6 and the epithelial-mesenchymal transition (EMT). Cell Cycle, 4, 1350-1352.

128. Bates, R. C., Bellovin, D. I., Brown, C., Maynard, E., Wu, B., \& Kawakatsu, H. (2005). Transcriptional activation of integrin beta6 during the epithelial-mesenchymal transition defines a novel prognostic indicator of aggressive colon carcinoma. J Clin Invest, 115, 339-347.

129. Araya, J., Cambier, S., Morris, A., Finkbeiner, W., \& Nishimura, S. L. (2006). Integrin-mediated transforming growth factor-beta activation regulates homeostasis of the pulmonary epithelialmesenchymal trophic unit. Am J Pathol, 169, 405-415.

130. Li, Y., Dai, C., Wu, C., \& Liu, Y. (2007). PINCH-1 promotes tubular epithelial-to-mesenchymal transition by interacting with integrin-linked kinase. J Am Soc Nephrol, 18, 2534-2543.

131. Bagnato, A., \& Rosano, L. (2007). Epithelial-mesenchymal transition in ovarian cancer progression: a crucial role for the endothelin axis. Cells Tissues Organs, 185, 85-94.

132. Oloumi, A., McPhee, T., \& Dedhar, S. (2004). Regulation of Ecadherin expression and beta-catenin/Tcf transcriptional activity by the integrin-linked kinase. Biochim Biophys Acta, 1691, 1-15.

133. Etienne-Manneville, S., \& Hall, A. (2002). Rho GTPases in cell biology. Nature, 420, 629-635.

134. Burridge, K. (2004). Wennerberg, K. Rho and Rac take center stage. Cell, 116, 167-179.

135. Sahai, E., \& Marshall, C. J. (2002). RHO-GTPases and cancer. Nat Rev Cancer, 2, 133-142.

136. Hall, A. (2005). Rho GTPases and the control of cell behaviour. Biochem Soc Trans, 33, 891-895.

137. Ridley, A. J. (2006). Rho GTPases and actin dynamics in membrane protrusions and vesicle trafficking. Trends Cell Biol, $16,522-529$.

138. Lozano, E., Betson, M., \& Braga, V. M. (2003). Tumor progression: Small GTPases and loss of cell-cell adhesion. Bioessays, 25, 452-463.

139. Cozzolino, M., Stagni, V., Spinardi, L., Campioni, N., Fiorentini, C., \& Salvati, E. (2003). p120 Catenin is required for growth factordependent cell motility and scattering in epithelial cells. Mol Biol Cell, 14, 1964-1977.

140. Anastasiadis, P. Z. (2007). p120-ctn: A nexus for contextual signaling via Rho GTPases. Biochim Biophys Acta, 1773, 34-46.

141. Bellovin, D. I., Bates, R. C., Muzikansky, A., Rimm, D. L., \& Mercurio, A. M. (2005). Altered localization of p120 catenin during epithelial to mesenchymal transition of colon carcinoma is prognostic for aggressive disease. Cancer Res, 65, 1093810945.
142. Zondag, G. C., Evers, E. E., ten Klooster, J. P., Janssen, L., van der Kammen, R. A., \& Collard, J. G. (2000). Oncogenic Ras downregulates Rac activity, which leads to increased Rho activity and epithelial-mesenchymal transition. $J$ Cell Biol, 149, 775-782.

143. Radisky, D. C., Levy, D. D., Littlepage, L. E., Liu, H., Nelson, C. M., \& Fata, J. E. (2005). Raclb and reactive oxygen species mediate MMP-3-induced EMT and genomic instability. Nature, $436,123-127$.

144. Clark, E. A., Golub, T. R., Lander, E. S., \& Hynes, R. O. (2000). Genomic analysis of metastasis reveals an essential role for Rock. Nature, 406, 532-535.

145. Hakem, A., Sanchez-Sweatman, O., You-Ten, A., Duncan, G., Wakeham, A., \& Khokha, R. (2005). Rock is dispensable for embryogenesis and tumor initiation but essential for metastasis. Genes Dev, 19, 1974-1979.

146. Nakaya, Y., Sukowati, E. W., Wu, Y., \& Sheng, G. (2008). RhoA and microtubule dynamics control cell-basement membrane interaction in EMT during gastrulation. Nat Cell Biol, 10, 765-775.

147. Hordijk, P. L., ten, Klooster, J. P., van, der, Kammen, R. A., Michiels, F., Oomen, L. C., \& Collard, J. G. (1997). Inhibition of invasion of epithelial cells by Tiam1-Rac signaling. Science, 278, 1464-1466.

148. Malliri, A., van, Es, S., Huveneers, S., \& Collard, J. G. (2004). The Rac exchange factor Tiam 1 is required for the establishment and maintenance of cadherin-based adhesions. J Biol Chem, 279, 30092-30098.

149. Malliri, A., van der Kammen, R. A., Clark, K., van der Valk, M., Michiels, F., \& Collard, J. G. (2002). Mice deficient in the Rac activator Tiam1 are resistant to Ras-induced skin tumours. Nature, 417, 867-871.

150. Krueger, E. W., Orth, J. D., Cao, H., \& McNiven, M. A. (2003). A dynamin-cortactin-Arp2/3 complex mediates actin reorganization in growth factor-stimulated cells. Mol Biol Cell, 14, 10851096.

151. Ballestrem, C., Wehrle-Haller, B., \& Imhof, B. A. (1998). Actin dynamics in living mammalian cells. J Cell Sci, 111, 1649-1658.

152. Suetsugu, S., Yamazaki, D., Kurisu, S., \& Takenawa, T. (2003). Differential roles of WAVE1 and WAVE2 in dorsal and peripheral ruffle formation for fibroblast cell migration. Dev Cell, 5, 595-609.

153. Orth, J. D., \& McNiven, M. A. (2006). Get off my back! Rapid receptor internalization through circular dorsal ruffles. Cancer Res, 66, 11094-11096.

154. Vieira, A. V., Lamaze, C., \& Schmid, S. L. (1996). Control of EGF receptor signaling by clathrin-mediated endocytosis. Science, 274, 2086-2089.

155. Dharmawardhane, S., Schurmann, A., Sells, M. A., Chernoff, J., Schmid, S. L., \& Bokoch, G. M. (2000). Regulation of macropinocytosis by p21-activated kinase-1. Mol Biol Cell, 11, 3341-3352.

156. Plattner, R., Kadlec, L., DeMali, K. A., Kazlauskas, A., \& Pendergast, A. M. (1999). c-Abl is activated by growth factors and Src family kinases and has a role in the cellular response to PDGF. Genes Dev, 13, 2400-2411.

157. Yang, Y., Pan, X., Lei, W., Wang, J., Shi, J., Li, F., \& Song, J. (2006). Regulation of transforming growth factor-beta 1-induced apoptosis and epithelial-to-mesenchymal transition by protein kinase A and signal transducers and activators of transcription 3. Cancer Res, 66, 8617-8624.

158. Finn, R. S., Dering, J., Ginther, C., Wilson, C. A., Glaspy, P., \& Tchekmedyian, N. (2007). Dasatinib, an orally active small molecule inhibitor of both the src and abl kinases, selectively inhibits growth of basal-type/"triple-negative" breast cancer cell lines growing in vitro. Breast Cancer Res Treat, 105, 319-326. 
159. Srinivasan, D., \& Plattner, R. (2006). Activation of Abl tyrosine kinases promotes invasion of aggressive breast cancer cells. Cancer Res, 66, 5648-5655.

160. Watanabe, T., Wang, S., Noritake, J., Sato, K., Fukata, M., \& Takefuji, M. (2004). Interaction with IQGAP1 links APC to Rac1, Cdc42, and actin filaments during cell polarization and migration. Dev Cell, 7, 871-883.

161. Etienne-Manneville, S., \& Hall, A. (2003). Cdc42 regulates GSK-3beta and adenomatous polyposis coli to control cell polarity. Nature, 421, 753-756.

162. Sharma, M., Leung, L., Brocardo, M., Henderson, J., Flegg, C., \& Henderson, B. R. (2006). Membrane localization of adenomatous polyposis coli protein at cellular protrusions: targeting sequences and regulation by beta-catenin. J Biol Chem, 281, 17140-17149.

163. Goicoechea, S. M., Arneman, D., \& Otey, C. A. (2008). The role of palladin in actin organization and cell motility. Eur $J$ Cell Biol, 87(8-9), 517-525.

164. Goicoechea, S., Arneman, D., Disanza, A., Garcia-Mata, R., Scita, G., \& Otey, C. A. (2006). Palladin binds to Eps8 and enhances the formation of dorsal ruffles and podosomes in vascular smooth muscle cells. J Cell Sci, 119, 3316-3324.

165. Ronty, M., Taivainen, A., Heiska, L., Otey, C., Ehler, E., \& Song, W. K. (2007). Palladin interacts with SH3 domains of SPIN90 and Src and is required for Src-induced cytoskeletal remodeling. Exp Cell Res, 313, 2575-2585.

166. Griffith, O. L., Melck, A., Jones, S. J., \& Wiseman, S. M. (2006). Meta-analysis and meta-review of thyroid cancer gene expression profiling studies identifies important diagnostic biomarkers. J Clin Oncol, 24, 5043-5051.

167. Matoskova, B., Wong, W. T., Salcini, A. E., Pelicci, P. G., \& Di, Fiore, P. P. (1995). Constitutive phosphorylation of eps8 in tumor cell lines: relevance to malignant transformation. Mol Cell Biol, $15,3805-3812$.

168. Yao, J., Weremowicz, S., Feng, B., Gentleman, R. C., Marks, J. R., \& Gelman, R. (2006). Combined cDNA array comparative genomic hybridization and serial analysis of gene expression analysis of breast tumor progression. Cancer Res, 66, 4065-4078.

169. Ryu, B., Jones, J., Hollingsworth, M. A., Hruban, R. H., \& Kern, S. E. (2001). Invasion-specific genes in malignancy: serial analysis of gene expression comparisons of primary and passaged cancers. Cancer Res, 61, 1833-1838.

170. Wang, W., Goswami, S., Lapidus, K., Wells, A. L., Wyckoff, J. B., \& Sahai, E. (2004). Identification and testing of a gene expression signature of invasive carcinoma cells within primary mammary tumors. Cancer Res, 64, 8585-8594.

171. Ronty, M. J., Leivonen, S. K., Hinz, B., Rachlin, A., Otey, C. A., \& Kahari, V. M. (2006). Isoform-specific regulation of the actinorganizing protein palladin during TGF-betal-induced myofibroblast differentiation. $J$ Invest Dermatol, 126, 2387-2396.

172. Ibarra, N., Pollitt, A., \& Insall, R. H. (2005). Regulation of actin assembly by SCAR/WAVE proteins. Biochem Soc Trans, 33, $1243-1246$.

173. LeClainche, C., \& Carlier, M. F. (2008). Regulation of actin assembly associated with protrusion and adhesion in cell migration. Physiol Rev, 88, 489-513.

174. Innocenti, M., Zucconi, A., Disanza, A., Frittoli, E., Areces, L. B., \& Steffen, A. (2004). Abil is essential for the formation and activation of a WAVE2 signalling complex. Nat Cell Biol, 6, 319327.

175. Iwaya, K., Norio, K., \& Mukai, K. (2007). Coexpression of Arp2 and WAVE2 predicts poor outcome in invasive breast carcinoma. Mod Pathol, 20, 339-343.

176. Iwaya, K., Oikawa, K., Semba, S., Tsuchiya, B., Mukai, Y., \& Otsubo, T. (2007). Correlation between liver metastasis of the colocalization of actin-related protein 2 and 3 complex and WAVE2 in colorectal carcinoma. Cancer Sci, 98, 992-999.

177. Khoury, H., Dankort, D. L., Sadekova, S., Naujokas, M. A., Muller, W. J., \& Park, M. (2001). Distinct tyrosine autophosphorylation sites mediate induction of epithelial mesenchymal like transition by an activated ErbB-2/Neu receptor. Oncogene, 20, 788-799.

178. Wang, L., Lee, J. F., Lin, C. Y., \& Lee, M. J. (2008). Rho GTPases mediated integrin alpha $\mathrm{v}$ beta 3 activation in sphingosine-1-phosphate stimulated chemotaxis of endothelial cells. Histochem Cell Biol, 129, 579-588.

179. Mori, H., Tomari, T., Koshikawa, N., Kajita, M., Itoh, Y., \& Sato, H. (2002). CD44 directs membrane-type 1 matrix metalloproteinase to lamellipodia by associating with its hemopexin-like domain. EMBO J, 21, 3949-3959.

180. Coopman, P. J., Do, M. T., Thompson, E. W., \& Mueller, S. C. (1998). Phagocytosis of cross-linked gelatin matrix by human breast carcinoma cells correlates with their invasive capacity. Clin Cancer Res, 4, 507-515.

181. Wang, W., Wyckoff, J. B., Frohlich, V. C., Oleynikov, Y., Huttelmaier, S., \& Zavadil, J. (2002). Single cell behavior in metastatic primary mammary tumors correlated with gene expression patterns revealed by molecular profiling. Cancer Res, 62, 6278-6288.

182. Svitkina, T. M., Bulanova, E. A., Chaga, O. Y., Vignjevic, D. M., Kojima, S., \& Vasiliev, J. M. (2003). Mechanism of filopodia initiation by reorganization of a dendritic network. $J$ Cell Biol, 160, 409-421.

183. Pelosi, G., Pastorino, U., Pasini, F., Maissoneuve, P., Fraggetta, F., \& Iannucci, A. (2003). Independent prognostic value of fascin immunoreactivity in stage I nonsmall cell lung cancer. $\mathrm{Br} J$ Cancer, 88, 537-547.

184. Hashimoto, Y., Shimada, Y., Kawamura, J., Yamasaki, S., \& Imamura, M. (2004). The prognostic relevance of fascin expression in human gastric carcinoma. Oncology, 67, 262270.

185. Rodriguez-Pinilla, S. M., Sarrio, D., Honrado, E., Hardisson, D., Calero, F., \& Benitez, J. (2006). Prognostic significance of basallike phenotype and fascin expression in node-negative invasive breast carcinomas. Clin Cancer Res, 12, 1533-1539.

186. Mongiu, A. K., Weitzke, E. L., Chaga, O. Y., \& Borisy, G. G. (2007). Kinetic-structural analysis of neuronal growth cone veil motility. J Cell Sci, 120, 1113-1125.

187. Saltel, F., Destaing, O., Bard, F., Eichert, D., \& Jurdic, P. (2004). Apatite-mediated actin dynamics in resorbing osteoclasts. Mol Biol Cell, 15, 5231-5241.

188. Linder, S. (2007). The matrix corroded: podosomes and invadopodia in extracellular matrix degradation. Trends Cell Biol, 17, 107-117.

189. Linder, S., \& Kopp, P. (2005). Podosomes at a glance. J Cell Sci, 118, 2079-2082.

190. Ayala, I., Baldassarre, M., Caldieri, G., \& Buccione, R. (2006). Invadopodia: a guided tour. Eur J Cell Biol, 85, 159-164.

191. Block, M. R., Badowski, C., Millon-Fremillon, A., Bouvard, D., Bouin, A. P., \& Faurobert, E. (2008). Podosome-type adhesions and focal adhesions, so alike yet so different. Eur J Cell Biol, 87 (8-9), 491-506.

192. Kelly, T., Yan, Y., Osborne, R. L., Athota, A. B., Rozypal, T. L., \& Colclasure, J. C. (1998). Proteolysis of extracellular matrix by invadopodia facilitates human breast cancer cell invasion and is mediated by matrix metalloproteinases. Clin Exp Metastasis, 16, 501-512.

193. Tague, S. E., Muralidharan, V., D, , \& Souza-Schorey, C. (2004). ADP-ribosylation factor 6 regulates tumor cell invasion through the activation of the MEK/ERK signaling pathway. Proc Natl Acad Sci U S A, 101, 9671-9676. 
194. Artym, V. V., Zhang, Y., Seillier-Moiseiwitsch, F., Yamada, K. M., \& Mueller, S. C. (2006). Dynamic interactions of cortactin and membrane type 1 matrix metalloproteinase at invadopodia: defining the stages of invadopodia formation and function. Cancer Res, 66, 3034-3043.

195. Angers-Loustau, A., Hering, R., Werbowetski, T. E., Kaplan, D. R., \& Del, Maestro, R. F. (2004). SRC regulates actin dynamics and invasion of malignant glial cells in three dimensions. Mol Cancer Res, 2, 595-605.

196. Clark, E. S., Whigham, A. S., Yarbrough, W. G., \& Weaver, A. M. (2007). Cortactin is an essential regulator of matrix metalloproteinase secretion and extracellular matrix degradation in invadopodia. Cancer Res, 67, 4227-4235.

197. Yamaguchi, H., Lorenz, M., Kempiak, S., Sarmiento, C., Coniglio, S., \& Symons, M. (2005). Molecular mechanisms of invadopodium formation: the role of the N-WASP-Arp2/3 complex pathway and cofilin. J Cell Biol, 168, 441-452.

198. Oxmann, D., Held-Feindt, J., Stark, A. M., Hattermann, K., Yoneda, T., \& Mentlein, R. (2008). Endoglin expression in metastatic breast cancer cells enhances their invasive phenotype. Oncogene, 27, 3567-3575.

199. Nakahara, H., Nomizu, M., Akiyama, S. K., Yamada, Y., Yeh, Y., \& Chen, W. T. (1996). A mechanism for regulation of melanoma invasion. Ligation of alpha6beta1 integrin by laminin $\mathrm{G}$ peptides. J Biol Chem, 271, 27221-27224.

200. Wyckoff, J., Wang, W., Lin, E. Y., Wang, Y., Pixley, F., \& Stanley, E. R. (2004). A paracrine loop between tumor cells and macrophages is required for tumor cell migration in mammary tumors. Cancer Res, 64, 7022-7029.

201. Yamaguchi, H., Pixley, F., \& Condeelis, J. (2006). Invadopodia and podosomes in tumor invasion. Eur J Cell Biol, 85, 213-218.

202. Rafii, S., \& Lyden, D. (2006). S100 chemokines mediate bookmarking of premetastatic niches. Nat Cell Biol, 8, 13211323.

203. Cortesio, C. L., Chan, K. T., Perrin, B. J., Burton, N. O., Zhang, S., \& Zhang, Z. Y. (2008). Calpain 2 and PTP1B function in a novel pathway with $\mathrm{Src}$ to regulate invadopodia dynamics and breast cancer cell invasion. J Cell Biol, 180, 957-971.

204. Webb, B. A., Jia, L., Eves, R., \& Mak, A. S. (2007). Dissecting the functional domain requirements of cortactin in invadopodia formation. Eur J Cell Biol, 86, 189-206.

205. Bowden, E. T., Onikoyi, E., Slack, R., Myoui, A., Yoneda, T., \& Yamada, K. M. (2006). Co-localization of cortactin and phosphotyrosine identifies active invadopodia in human breast cancer cells. Exp Cell Res, 312, 1240-1253.

206. Bharti, S., Inoue, H., Bharti, K., Hirsch, D. S., Nie, Z., \& Yoon, H. Y. (2007). Src-dependent phosphorylation of ASAP1 regulates podosomes. Mol Cell Biol, 27, 8271-8283.

207. Badowski, C., Pawlak, G., Grichine, A., Chabadel, A., Oddou, C., \& Jurdic, P. (2008). Paxillin Phosphorylation Controls Invadopodia/Podosomes Spatiotemporal Organization. Mol Biol Cell, 19, 633-645.

208. Oikawa, T., Itoh, T., \& Takenawa, T. (2008). Sequential signals toward podosome formation in NIH-src cells. J Cell Biol, 182(1), $157-169$.

209. Seals, D. F., Azucena Jr., E. F., Pass, I., Tesfay, L., Gordon, R., \& Woodrow, M. (2005). The adaptor protein Tks5/Fish is required for podosome formation and function, and for the proteasedriven invasion of cancer cells. Cancer Cell, 7, 155-165.

210. Mueller, S. C., \& Chen, W. T. (1991). Cellular invasion into matrix beads: localization of beta 1 integrins and fibronectin to the invadopodia. J Cell Sci, 99, 213-225.
211. Deryugina, E. I., Ratnikov, B., Monosov, E., Postnova, T. I., DiScipio, R., \& Smith, J. W. (2001). MT1-MMP initiates activation of pro-MMP-2 and integrin alphavbeta3 promotes maturation of MMP-2 in breast carcinoma cells. Exp Cell Res, 263, 209-223.

212. Galliher, A. J., \& Schiemann, W. P. (2007). Src phosphorylates Tyr284 in TGF-beta type II receptor and regulates TGF-beta stimulation of p38 MAPK during breast cancer cell proliferation and invasion. Cancer Res, 67, 3752-3758.

213. Terauchi, M., Kajiyama, H., Yamashita, M., Kato, M., Tsukamoto, H., \& Umezu, T. (2007). Possible involvement of TWIST in enhanced peritoneal metastasis of epithelial ovarian carcinoma. Clin Exp Metastasis, 24, 329-339.

214. Nakahara, H., Mueller, S. C., Nomizu, M., Yamada, Y., Yeh, Y., \& Chen, W. T. (1998). Activation of betal integrin signaling stimulates tyrosine phosphorylation of p190RhoGAP and membrane-protrusive activities at invadopodia. J Biol Chem, 273, 9-12.

215. Chuang, Y. Y., Tran, N. L., Rusk, N., Nakada, M., Berens, M. E., \& Symons, M. (2004). Role of synaptojanin 2 in glioma cell migration and invasion. Cancer Res, 64, 8271-8275.

216. Sakurai-Yageta, M., Recchi, C., Le, Dez, G., Sibarita, J. B., Daviet, L., \& Camonis, J. (2008). The interaction of IQGAP1 with the exocyst complex is required for tumor cell invasion downstream of Cdc42 and RhoA. J Cell Biol, 181, 985-998.

217. Buccione, R., Orth, J. D., \& McNiven, M. A. (2004). Foot and mouth: podosomes, invadopodia and circular dorsal ruffles. Nat Rev Mol Cell Biol, 5, 647-657.

218. Gimona, M., Buccione, R., Courtneidge, S. A., \& Linder, S. (2008). Assembly and biological role of podosomes and invadopodia. Curr Opin Cell Biol, 20, 235-241.

219. Vignjevic, D., \& Montagnac, G. (2008). Reorganisation of the dendritic actin network during cancer cell migration and invasion. Semin Cancer Biol, 18, 12-22.

220. Weaver, A. M. (2008). Invadopodia. Curr Biol, 18, 362-364.

221. Varon, C., Tatin, F., Moreau, V., Van Obberghen-Schilling, E., Fernandez-Sauze, S., Reuzeau, E., et al. (2006). Transforming growth factor beta induces rosettes of podosomes in primary aortic endothelial cells. Mol Cell Biol, 26, 3582-3594.

222. Frame, M. C. (2004). Newest findings on the oldest oncogene; how activated src does it. $J$ Cell Sci, 117, 989-998.

223. Xie, L., Law, B. K., Aakre, M. E., Edgerton, M., Shyr, Y., Bhowmick, N. A., et al. (2003). Transforming growth factor beta-regulated gene expression in a mouse mammary gland epithelial cell line. Breast Cancer Res, 5, S187-198.

224. Fonsatti, E., Altomonte, M., Nicotra, M. R., Natali, P. G., \& Maio, M. (2003). Endoglin (CD105): a powerful therapeutic target on tumor-associated angiogenetic blood vessels. Oncogene, 22, 6557-6563.

225. Mercado-Pimentel, M. E., Hubbard, A. D., \& Runyan, R. B. (2007). Endoglin and Alk5 regulate epithelial-mesenchymal transformation during cardiac valve formation. Dev Biol, 304, 420-432.

226. Lua, B. L., \& Low, B. C. (2004). BPGAP1 interacts with cortactin and facilitates its translocation to cell periphery for enhanced cell migration. Mol Biol Cell, 15, 2873-2883.

227. Head, J. A., Jiang, D., Li, M., Zorn, L. J., Schaefer, E. M., Parsons, J. T., \& Weed, S. A. (2003). Cortactin tyrosine phosphorylation requires Rac1 activity and association with the cortical actin cytoskeleton. Mol Biol Cell, 14, 3216-3229.

228. Lee, S. H. (2005). Interaction of nonreceptor tyrosine-kinase Fer and p120 catenin is involved in neuronal polarization. Mol Cells, 20, 256-262. 